\title{
A new methodology to predict damage tolerance based on compliance via global-local analysis
}

\author{
Gilberto Gomes, Thiago Arnaud A Oliveira, Alvaro Martins Delgado Neto, Luciano Mendes \\ Bezerra \\ University of Brasilia, Brazil \\ ggomes@unb.br, http://orcid.org/0000-0002-8385-9042 \\ eng.thiagoarnaud@gmail.com, bttp://orcid.org/0000-0002-8220-5557 \\ alvaro.martins.bok@gmail.com, bttp:/ / orcid.org/0000-0002-4900-9116 \\ lmbz@unb.br,bttp://orcid.org/0000-0002-5789-9649
}

\begin{abstract}
Over the years several design philosophies to address fatigue have been developed trying to combine structural safety and economy with aircraft manufacturing and operating processes. The safe-life approach consists of designing and manufacturing an aeronautical structure to be safe throughout its useful life. This approach results in factors that oversize structural elements to prevent possible failure and evidently incurs high design costs. Alternatively, a damage tolerance concept-based approach assumes that the structure, even when damaged, is able to withstand the actions for which it was designed until the detection of a crack due to fatigue or other defects during its operation. This research proposes a new methodology to address the damage tolerance problem in which twodimensional global-local analysis at different levels of external requests will be made by means of compliance, aimed at finding a relationship between fatigue life and the Paris' constant. Moreover, the study uses the BemCracker2D program for simulating two-dimensional crack growth. This methodology has proved to be an efficient alternative applicable to damage tolerance analysis.
\end{abstract}

KEYwORDs. Compliance; Damage tolerance; Fatigue; Global-local analysis Aircraft fuselage; BEM.

\section{OPEN ACCESS}

Citation: Gomes, G., Oliveira, T. A. A., Delgado Neto, A. M., Bezerra, L. M., A new methodology based on compliance to predict damage tolerance by the boundary element method, Frattura ed Integrità Strutturale, xx (2021) 211-230.

Received: 15.06 .2021

Accepted: 27.07.2021

Published: 01.10.2021

Copyright: (C) 2020 This is an open access article under the terms of the CC-BY 4.0, which permits unrestricted use, distribution, and reproduction in any medium, provided the original author and source are credited.

\section{INTRODUCTION}

$\mathrm{T}$ he National Transportation Safety Board [1] and Wanhill [2], have highlighted a number of documented studies to interpret the cause of airplane accidents due to fatigue processes such as those with the Comet and the Boeing 737-200. Sanford [3] states that all such structures are subject to fatigue, with cracks starting at the edges and growing until reaching critical size for brittle failure to occur, even when subjected to permanent loads only. Unlike 
structures that are plastically overloaded, where large deformations occur before failure, those caused by fatigue occur suddenly, without warning (brittle failure). This proves to be a big problem as it makes it impossible to take preventive measures before the complete rupture, so information related to the variable load over time and, particularly, its effect on cracks is of fundamental importance for predicting the behavior of the structure as a whole.

Over the years, several fatigue design philosophies have evolved trying to combine structural safety and economy in aircraft manufacturing and operating processes. The first approach, called safe-life, consists of designing and manufacturing an aircraft structure that is safe for its entire lifetime. To that end, the most extreme situations of foreseeable fatigue requirements arising during operation must be considered in the prototype tests. This methodology results in factors that oversize the structural elements in order to prevent the possibility of failure. It is an approach that evidently leads to high design costs and is not capable of guaranteeing security as to whether an unforeseen failure may occur during project life. Rationally, a new philosophy has been developed based on the concept of damage tolerance. In this methodology, it is assumed that the structure, even when damaged, is able to withstand the actions for which it was designed until the detection of a fatigue crack or other defects during its operation. The unit is then checked, repaired and put back into service until the end of its useful life. Palmberg [4] has been a pioneer in this new concept, performing a statistical analysis to control fatigue crack propagation and considering inspection intervals to keep the probability of complete failure low. Later, Wanhill [5,6] examined damage tolerance in the use of aluminum alloys for aircraft structural applications. Newman Jr. [7,8] has suggested that fatigue damage can be characterized by crack size. Schijve [9] proposed some aspects of the design, predictions and experiments associated with the same concept in aircraft structures. Barter and Molent [10] showed that the load cycles have a direct linear relationship with the logarithm of the crack size and that the largest cracks formed grow approximately exponentially (the so-called "main crack" methodology) [11] from small discontinuities inherent to the material, as soon as an aircraft enters into service [12]. Currently, the concept of damage tolerance is applied to aircraft with composite structures [13-16] in multiple crack analysis [17] and in shape optimization projects $[18,19]$. Probabilistic studies on damage tolerance are based on fabrication components [20] and fatigue life dispersion from an initial defect distribution [21]. Other works relate damage tolerance to computational methods, using Finite Element Method [22] and Extended Finite Element Method (XFEM) [23], Boundary Element Method (BEM) [24] and Dual Boundary Element Method (DBEM) [25].

In an aircraft fuselage, the evaluation of Fracture Mechanics (FM) parameters such as Stress Intensity Factor (SIF), number of load cycles and stress and displacement fields becomes difficult due to the complex nature of the panel details: brackets, shear clips, rivets, etc. On the other hand, knowledge of those parameters is of paramount importance for understanding the nature of the damage process, especially under the action of dynamic loads.

Thus, designers are always looking for fast and reliable simulation methods that can produce accurate average data from these parameters to avoid damage processes and, consequently, the occurrence of accidents. Automation is seen as a key point, allowing for the evaluation of various analyzes as a means for conducting parametric studies and resulting in design optimization [26]. Among the several numerical methods for fracture modeling and analysis, DBEM has been consolidated and has the following advantages: simplified modeling of the crack area, direct SIF calculation, reduced execution times and accurate simulation of crack growth [27-29]. The behavior of a solid, discretizing only its contours, enables the analysis of the thousands of simulations necessary for a probabilistic study and, using DBEM, it is possible to study the defects, predicting the fatigue behavior, especially the damage process, multiple sites damage and reliability analysis, among others [30-34].

This work aims to find a solution for the damage tolerance problem detected in [35]. For that, two-dimensional globallocal analyzes will be carried out under different levels of external demands through compliance. The method aims to find a relationship between fatigue life and Paris' constants. Furthermore, a homemade software called BemCracker2D and its GUI BEMLAB2D version will be used for modeling and analysis of two-dimensional elastostatic problems involving cracks, which are based on the BEM and DBEM.

\section{LITERATURE REVIEW}

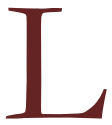

opez [36] presents an extensive review of the uncertainties involved in the monitoring of structural damage in aircraft addressing the existing methods developed for the problem of uncertainty in the areas of damage diagnosis, prognosis and control. Newman Jr. [8] predicts the fatigue life of various metallic materials under different loading conditions. This study made it possible to express crack growth as a function of the effective Stress Intensity Factor interval. The results obtained were compared with experiments on notched and unnotched specimens of aluminum and steel alloys. Fatigue is commonly represented by the study of [37]. Those authors made a fundamental 
contribution to the modeling of cracks in solids subjected to cyclic loads from the Paris-Erdogan Law, also called $d a / d N$, which relates the number of fatigue cycles with the crack size.

Palmberg [4] is one of the pioneers when it comes to considering the concept of damage tolerance. That author performs a statistical analysis to control the propagation of fatigue cracks and considers inspection intervals in order to ensure that the probability of complete failure of the structure is always kept low. Pyo [38] deals with an alternative method for analyzing fatigue damage in aircraft structures. The author developed a methodology called Elastic Finite Element Alternating Method (EFEAM) to predict the maximum load capacity in cracked panels highlighting the Multi Site Damage (MSD) effect. Also in the same study, an analytical solution for a crack line in an infinite metal sheet is developed and as a result the author demonstrates that the classical LEFM approximation overestimates the load capacity.

Jeong [39] presents a method for predicting the MSD threshold and also widespread damage to fuselages saying that the problem of widespread damage is the reduction in the residual strength of the structure below the tolerance while the MSD threshold refers to the point in useful life when there is fatigue coalescence (linkup) of two adjacent cracks still at the allowable stress level. The presented methodology determines a threshold value from the analysis of the combination of residual strength and fatigue crack growth results evaluated through laboratory tests. For that model, the results for the fatigue damage threshold were between 32,000 and 40,000 cycles and for the MSD threshold, about 70,000 cycles.

Platz [40] points out that fatigue cracks in lightweight shells or panel structures can lead to major failures when used for sealing or cargo transport. In his research, that author investigates the application of piezoelectric systems applied to the surface of a thin cracked aluminum panel to reduce fatigue crack propagation. With the reduction of propagation, uncertainties in the strength of the structure, which remain even when the structure is used under damage tolerance conditions such as in an aircraft fuselage, can be reduced. Piezoelectrics act by inducing compressive forces at the crack tip to reduce cyclic SIF. As a result, it has been statistically highlighted using experimental samples that the crack propagation rate significantly reduces.

Khan [41] has examined low cycle fatigue in aluminum Al 2024-T351 plate. Experimental analysis was performed for both monotonic and cyclic loading, using imaging technology to detect the crack start site. Breitbarth [42], based on biaxial tests with samples arranged in a cross, studied cracks in fuselage sections between the wing and tail of the aircraft, obtaining maximum SIF's values for metallic parts. The experimental results from digital images were compared with the analytical ones, obtaining studies of SIF's, J-Integral, plastic zone, and crack closure effects. Finally, the publications of [9] and [43] revealed that a fuselage subjected to compression testing to the Ultimate Limit State (ULS) and then fatigue tested had improved results due to residual compressive stresses. Those tensions were able to delay the development of cracks.

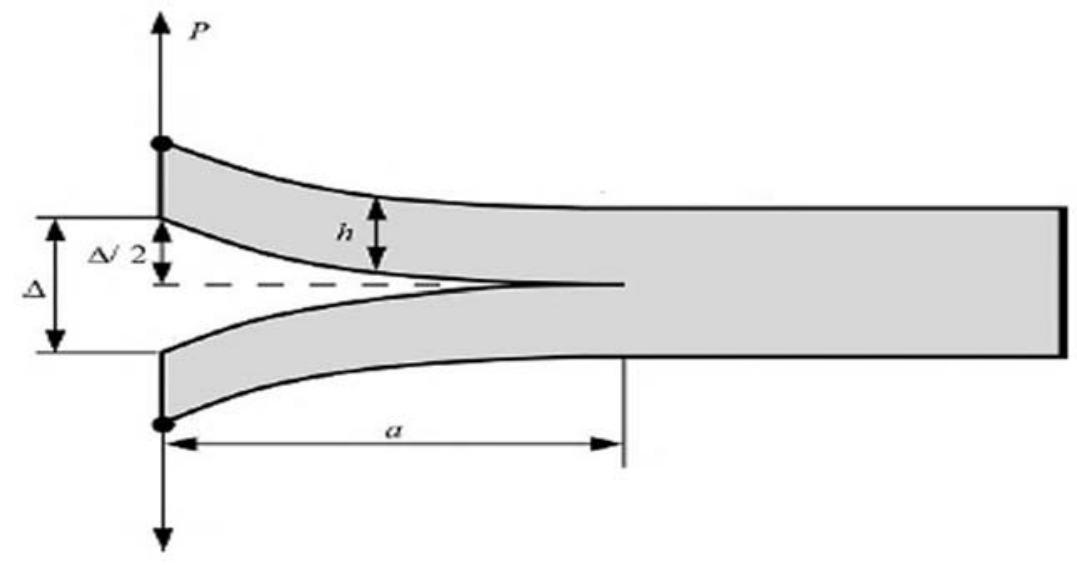

Figure 1: Double cantilever beam specimen requested by traction.

\section{BASIC FORMULATION}

his section presents the basic formulation of the main topics related to the methodology, namely, compliance and fatigue life.

\section{Compliance}

Compliance is the magnitude that represents the inverse of rigidity. Mathematically it is determined by: 


$$
C=\frac{\delta}{P}
$$

where $\delta$ is the displacement from an applied load P. In Fig. $1, \delta=\Delta / 2$.

\section{Fatigue Life}

Fatigue life can be represented by the Paris' Law. This law relates the crack propagation rate $(d a / d N)$ to the variation of the Stress Intensity Factor $(\Delta K)$ :

$$
\frac{d a}{d N}=C \cdot \Delta K^{m}
$$

where $C$ and $m$ are material constants, determined experimentally, $a$ is the crack size, $N$ is the number of loading cycles and $\Delta K$ is the variation of the Stress Intensity Factor. Developing Eqn. (2), the classic condition of the number of cycles, which varies from an initial crack $a_{0}$ that can be detected by conventional methods, to a critical length $a_{c}$, as determined by:

$$
N=\frac{1}{C} \int_{a_{0}}^{a_{c}} \frac{d a}{\Delta K^{m}}<N_{t o t}
$$

where $N$ is the number of cycles needed to increase the initial size crack and $N_{t o t}$ is the expected number of cycles over the life. This variation between the number of cycles of the initial crack $N_{0}$ and the critical $N_{c}$, when a safety factor (SF) is applied, is defined as the inspection interval to be adopted, mathematically represented by:

$$
\frac{N_{c}-N_{0}}{S F}
$$

\section{MATERIAL AND METHODS}

7 his section presents the computational technique developed for optimizing the fatigue life of aircraft fuselage parts through compliance. The technique aims to find the relationship between the physical parameters of the Paris' Law material $(C, m)$, such that the fatigue life equals that defined in the project. Moreover, a brief description will be made of the computational tools used in the global-local modeling and analysis process (BEMLAB2D and BemCracker2D softwares) in order to corroborate the presented methodology. This technique is based on the four steps of the following algorithm:

1) From the model in BEMLAB2D GUI by the user, the number of cycles required, or project, is defined $\left(n^{*}\right)$;

2) The algorithm computes the stress field in the macro analysis and locates the stress peak before reaching plastification, thus enabling the elastic analysis;

3) The algorithm positions the micro element at the stress peak found in step 2 , and calculates the number of cycles for which compliance reaches $3 C\left(N_{3 C}\right)$;

4) The algorithm, considering the initial fuselage defects (hole size and crack lengths), obtains a series of physical parameters of the material to be used $(C$ and $m)$ taking the number of cycles of the minimum instability compliance $\left(N_{3 C}\right)$ to be that defined by the user $\left(n^{*}\right)$. For example, if the designer wants to obtain the instability at $n^{*}=6 \times 10^{12}$, the optimization will show which series of physical parameters $\left(C\right.$ and $m$ ) the material needs to have so that it takes $N_{3 C}$ to the number of cycles defined in the design $\left(n^{*}\right)$, as illustrated in Fig. 2.

\section{BemLab2D GUI}

The BemLab2D software [44] is a graphic interface for manipulating two-dimensional models of boundary elements, allowing geometric information, boundary conditions and physical attributes to be managed in an efficient and userfriendly way. BemLab2D works both as a pre-processor when defining the geometric model of the problem, by associating physical attributes to the geometry and by generating the boundary elements mesh, and as a post-processor 
when used to visualize the data provided by BemCracker2D, as deformed graphs, SIF's, number of cycles and crack propagation, among others.

Fig. 3 illustrates these features.
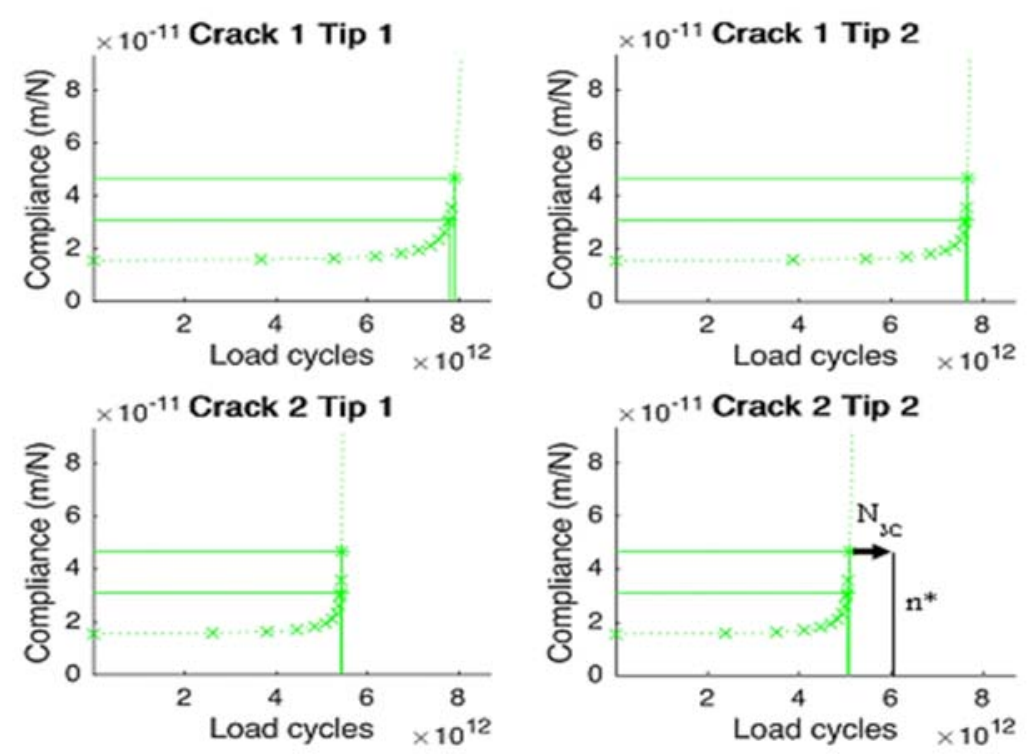

Figure 2: Optimization of the minimum number of cycles $\left(N_{3 C}\right)$ (fatigue life) for the number of design cycles $\left(n^{*}\right)$.

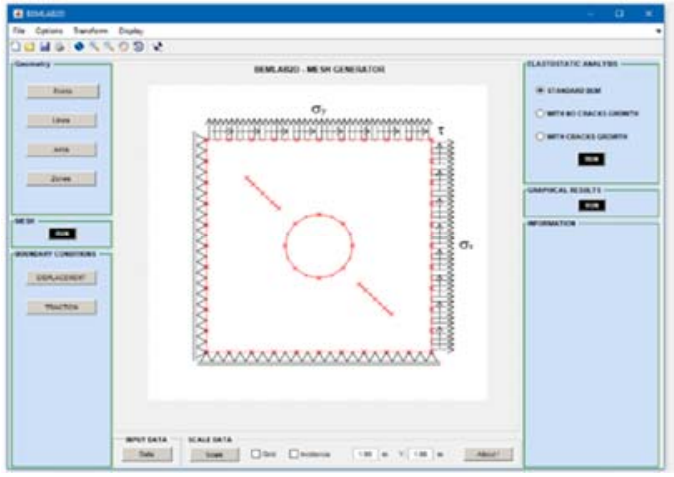

(a)

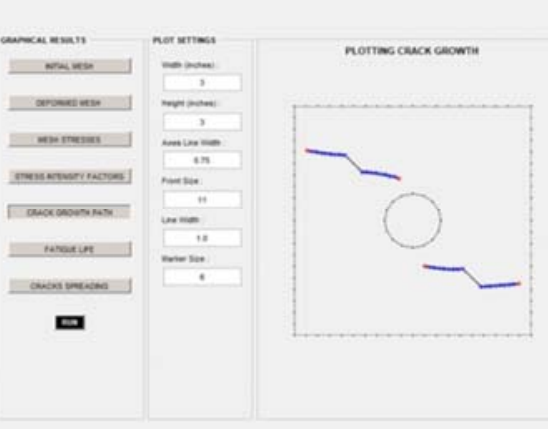

(b)

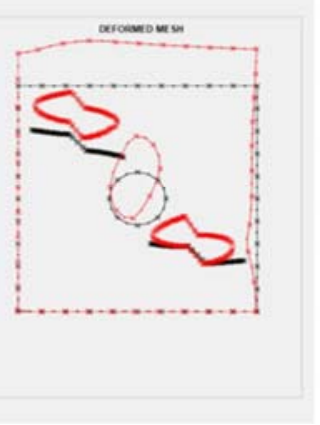

(c)

Figure 3: BEMLAB2D GUI; a) Modelling; b) Crack growth view; c) Deformed mesh view.

This graphical interface, for pre- and post-processing, is able to represent the macro and micro models by boundary elements, as detailed in the following sections.

\section{BemCracker2D Program}

BemCracker2D [45-48] is the processor program for elastostatic analysis of $2 \mathrm{D}$ problems. It is written in C++ language and entirely structured on the concepts of Object Oriented Programming (OOP) in order to perform analyzes using the Boundary Elements Method. Here, the module III (DBEM with propagation) of BemCracker2D is used, which consists in: Stress Analysis with standard BEM - SIF's Evaluation (J-Integral) - Direction/Correction of Crack Growth - Fatigue Life Evaluation (Paris' Law) and Coalescence of multiple cracks (linkup).

This software was developed from the standard BEM modeling and the incremental analysis strategy for problems with cracks [49,50]. For analysis of Fracture Mechanics problems, BemCracker2D calculates elastic stresses using the conventional BEM and performs incremental analysis of the crack extension using the DBEM. SIFs are computed for each increment through the J-integral, the propagation direction by the three classical criteria in the literature, although 
here the maximum circumferential stress is used, and the crack growth rate by one modified Paris' equation, which uses an equivalent SIF considering fracture modes I and II.

\section{COMPUTATIONAL TECHNIQUE}

7 he technique developed is divided into two analyses: Macro, which shows the place where the stress peak occurs; and Micro, which shows the number of critical fatigue life cycles. In this case, there is a main program that performs the interaction between the global and local analyses, as well as the link between the BemLab2D interface and the processing by BemCracker2D.

\section{Macro Analysis - pre-processing}

Initially, the modeling of the fuselage is performed in BemLab2D, obtaining the data referring to the physical parameters and the boundary element mesh, such as the nodal coordinates, mesh topology, traction and displacement boundary conditions, etc. As an example, the model in Fig. 4 was adopted, which consists of a plate with normal P and shear Q external loads and displacement restriction in the other nodes.

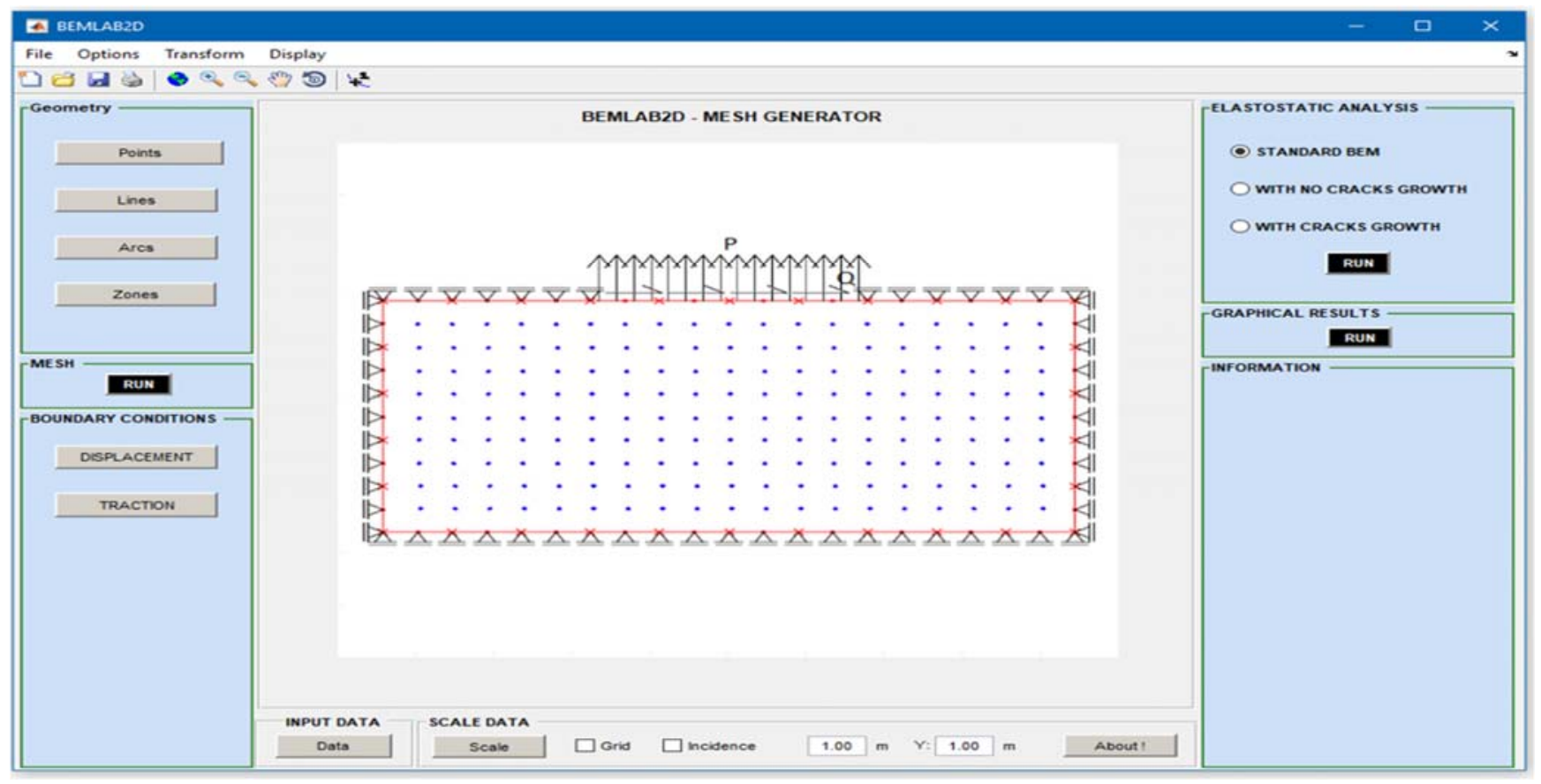

Figure 4: Global model and internal points.

From the initial model in Fig. 4, the algorithm creates the internal points for the calculation of the stress field, by BemCracker2D. The generated set of internal points is only intended to obtain a uniform grid of points to enable the plots of stress field and, therefore, it is not a mandatory requirement of the BEM.

\section{Macro Analysis - post-processing}

After obtaining the internal stress fields of the macro model, by BemCracker2D, the stress fields $\sigma_{\mathrm{x}}, \sigma_{\mathrm{y}}$ and $\tau_{\mathrm{xy}}$ are obtained, as illustrated, respectively, in Figs. 5, 6 and 7.

With these stress fields, one can find the critical location, or a peak that considers the three stresses together. For this, the von Mises criterion is used - see Fig. 8. It is noteworthy that the von Mises criterion was adopted only to identify the peak, still in the elastic regime; there is no plasticity analysis, since the algorithm is recommended for the elastic regime. Thus, if other criteria such as Tresca are adopted, for example, there will be no significant change in the position of the peak.

From the stress peak obtained in the macro model highlighted in Fig. 8, the micro model analysis is shown in the following item. 

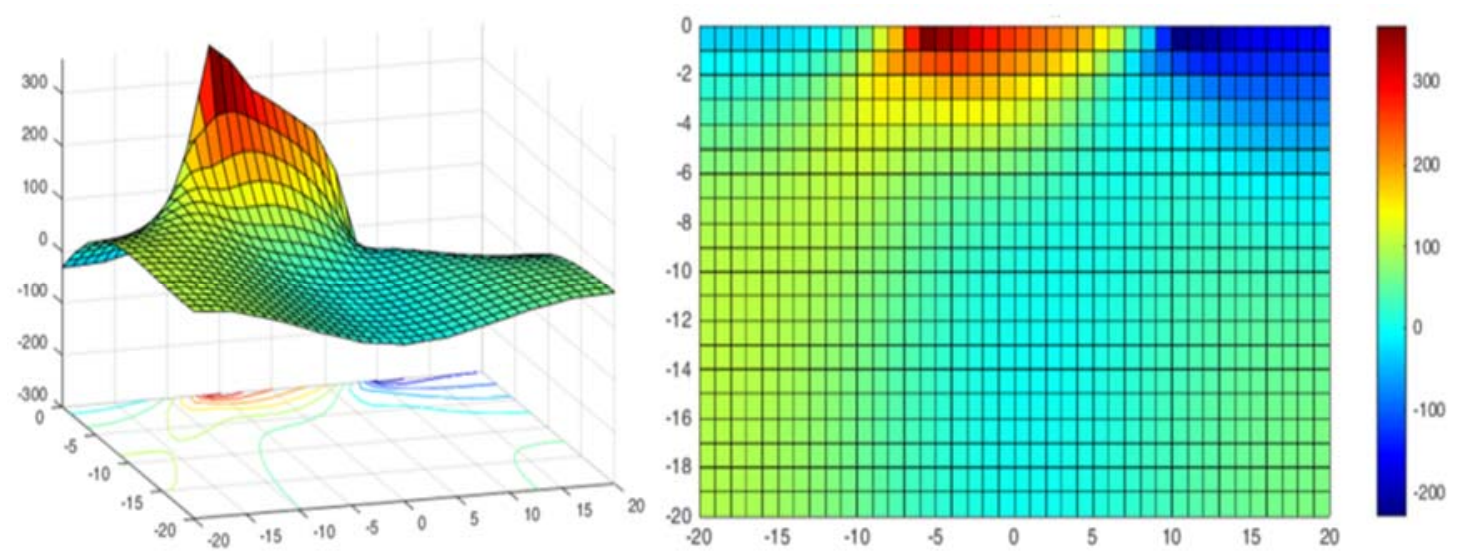

Figure 5: X-Normal stress field $\left(\sigma_{\mathrm{x}}\right)$.
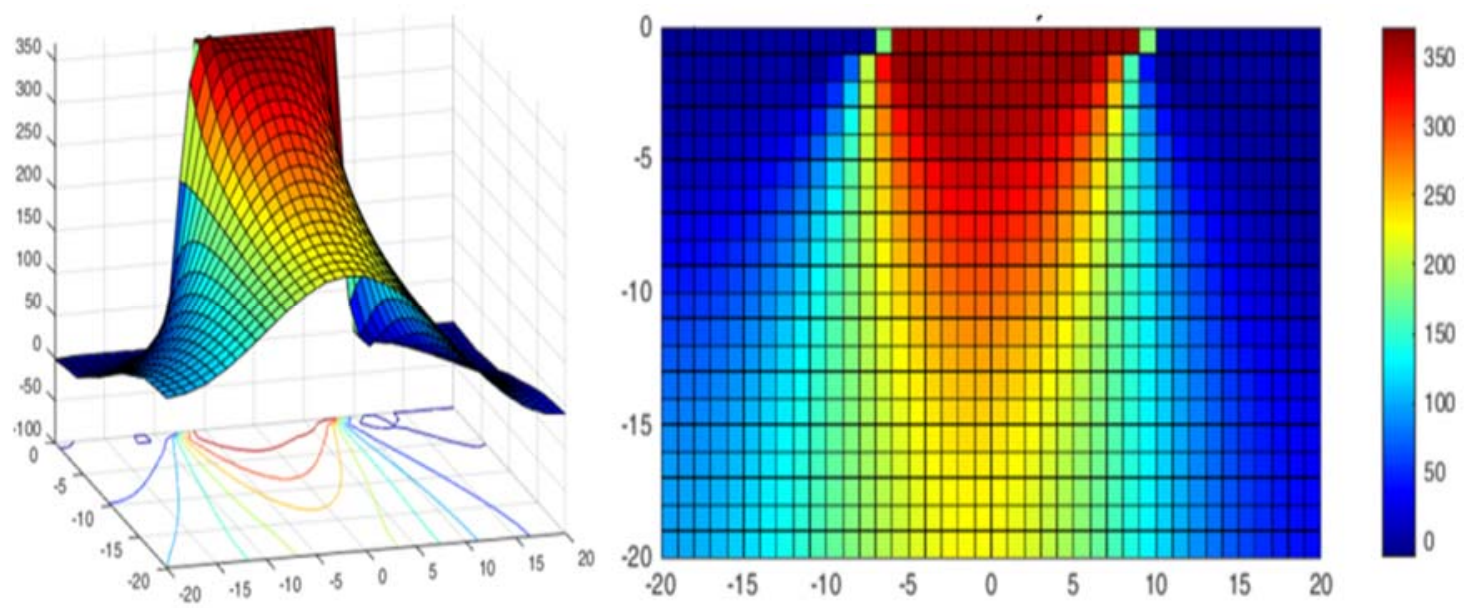

Figure 6: Y-Normal stress field $\left(\sigma_{y}\right)$.
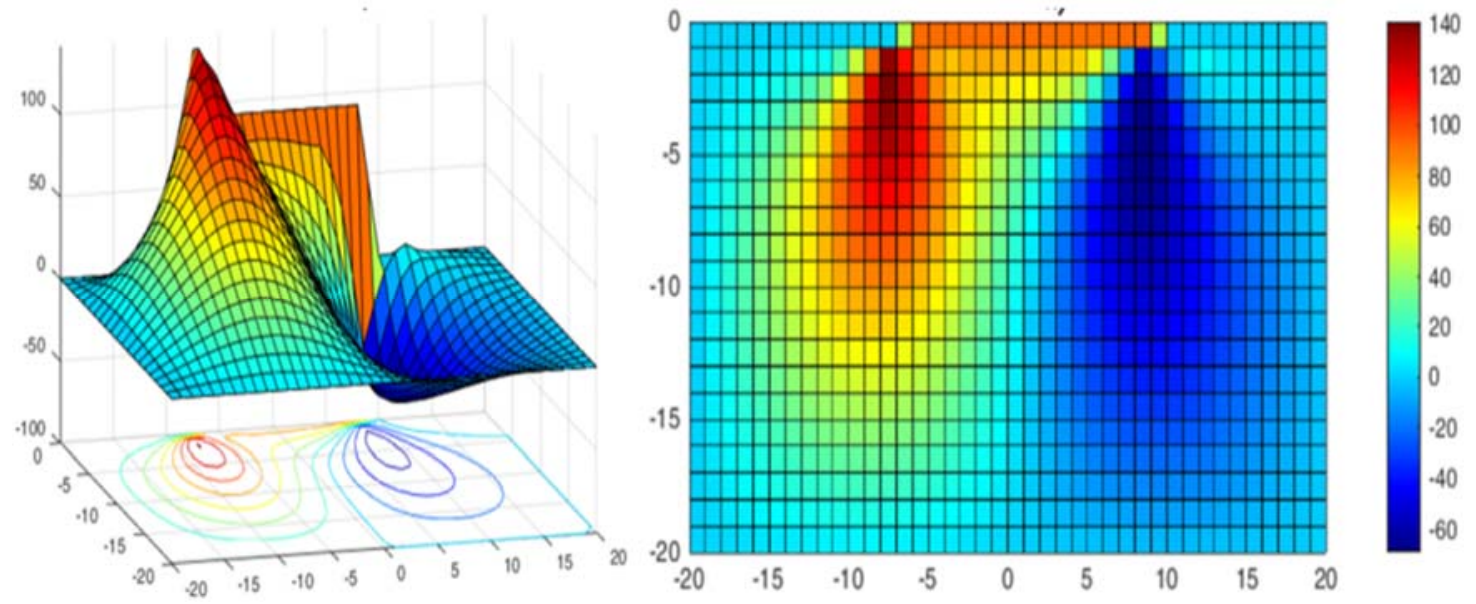

Figure 7: Shear stress field $\left(\tau_{\mathrm{xy}}\right)$. 

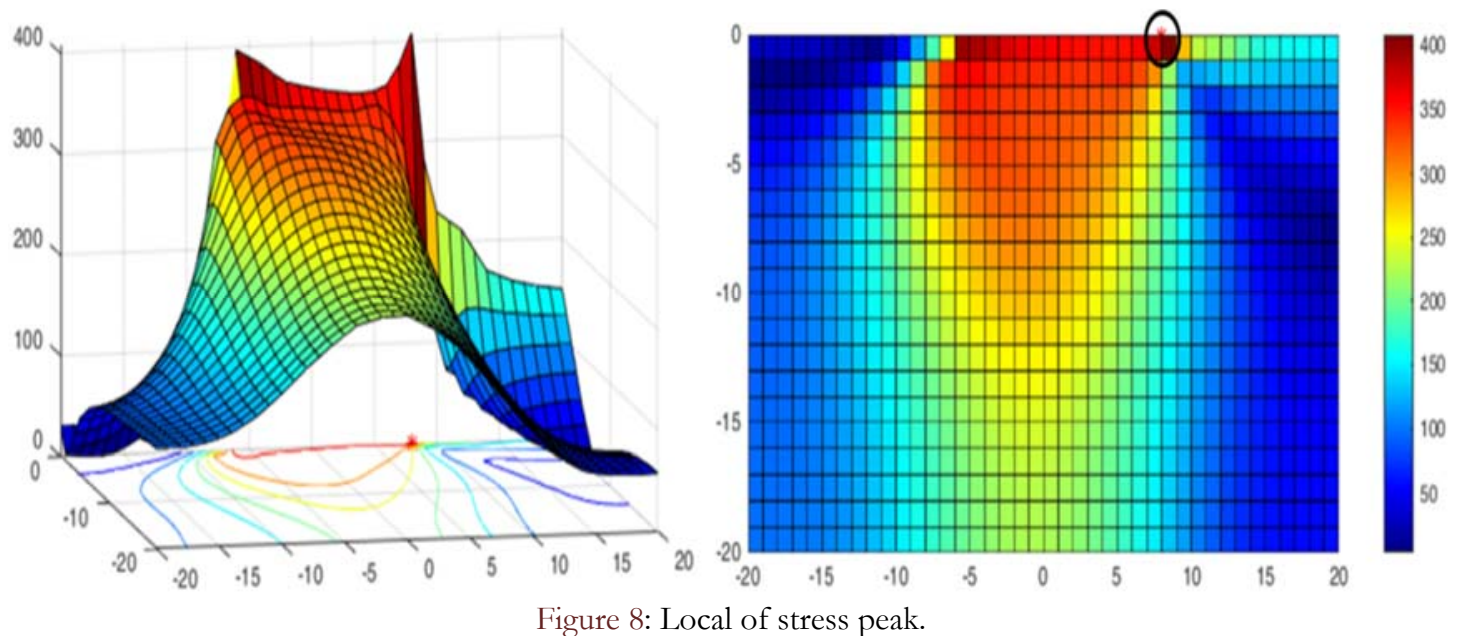

\section{Micro Analysis}

The micro model represented has a square shape with an edge size of $1 \mathrm{~cm}$ with initial flaws characterized by a central hole of radius $r$ and two cracks with sizes L1 and L2 representing the upper and lower cracks, respectively. The micro-model size and the initial defects are among the main problems in a multi-scale analysis, especially in techniques in which physical quantities are transferred from the micro-scale to the global scale, as performed in homogenization techniques [51]. Numerous researchers have addressed this problem over the years [52-56]. In this work, the values used reflect the effective size of supposed initial faults, however, a probabilistic methodology with BEM - using BemCracker2D, allows the initial defects to be modeled under different sizes. Thus, the micro analysis is performed at the peak location of the stress field, since, as this is the most unfavorable situation, all other positions would naturally be met. Continuing with the example adopted in [35], the peak is shown in Fig. 8 and the positioning of the micro model is shown in

Fig. 9 (a). In this case, the stresses are taken from the stress field at this point and applied on the right and upper edge with a fatigue load ratio $(\mathrm{R})$ equal to 0.5 and displacement constraint on the left and lower edges,

Fig. 9 (b). Here, 64 elements and 128 geometric nodes were considered, with quadratic continuous elements arranged on the edges and in the central circular hole, and quadratic discontinuous elements representing the cracks in the proportion 0.2-0.3-0.3-0.2. The elements were distributed as follows: 10 on each outer edge, adding 40, with a distance of 0.05 between them; 8 in the central circular hole and 8 in each crack, as shown in

Fig. 9 (c).

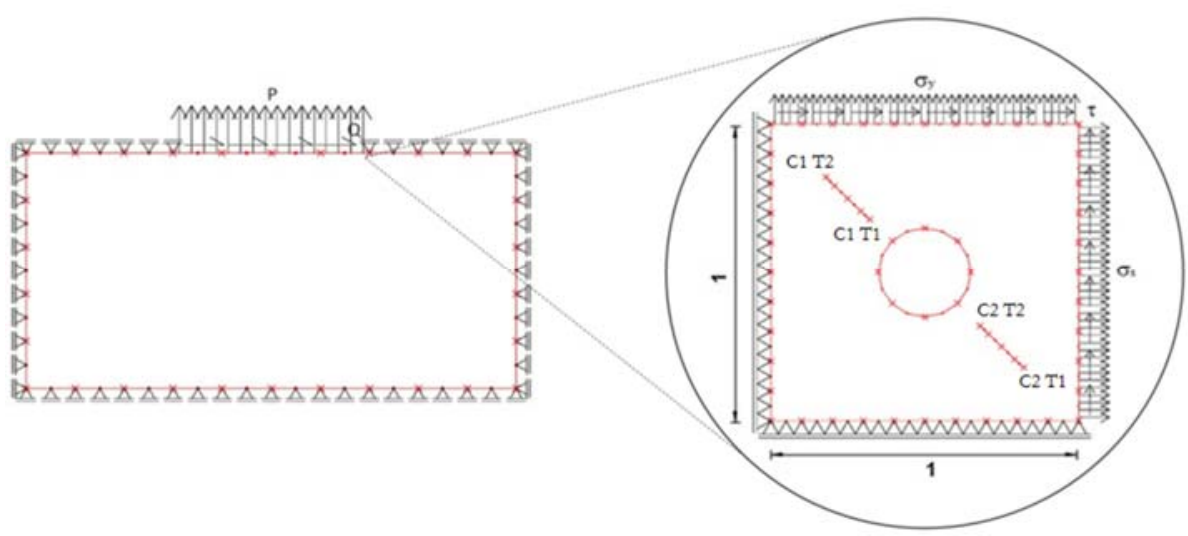

(a)

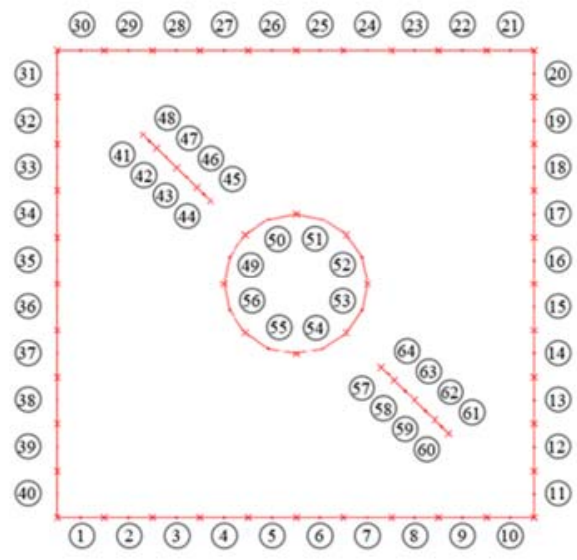

(c)

Figure 9: Micro model; a) local of stress peak; b) micro model modelling; c) BEM mesh.

From the micro model, BemCracker2d processes the incremental analysis and, at each crack advance, it brings as results the number of cycles and the mesh displacement, necessary for the compliance calculation from the average of the displacements of each edge and the respective tension on the considered edge (right or upper). 
Fig. 10 (a) shows the propagation path and the respective number of cycles and, and Fig. 10 (b) shows the mesh deformation.

In Fig. 11, each point, from left to right, represents an increment of the crack from Fig. 10 (a). The initial compliance, before the crack propagation, is on the abscissa axis, and, with each propagation increment, the plate loses rigidity and exponentially increases the compliance versus cycles ratio. From these points, a curve fit corresponding to a spline is created, resulting in the curves in Fig. 12, from which it is obtained the number of cycles corresponding to $2 \mathrm{x}$ initial compliance and $3 \mathrm{x}$ initial compliance. The number of cycles referring to $3 \mathrm{x}$ initial compliance is considered unstable, as from this point onwards compliance tends to infinity.

The results in Fig. 12 refer to Tip 1 of Crack 1 (Crack 1 Tip 1), see Fig. 9 (b). Fig. 13 presents the cycle number results for the four crack tips. For the purpose of damage tolerance, the smallest number of cycles that reach instability in $3 \mathrm{x}$ initial compliance $\left(\mathrm{N}_{3} \mathrm{C}\right)$ should be considered.

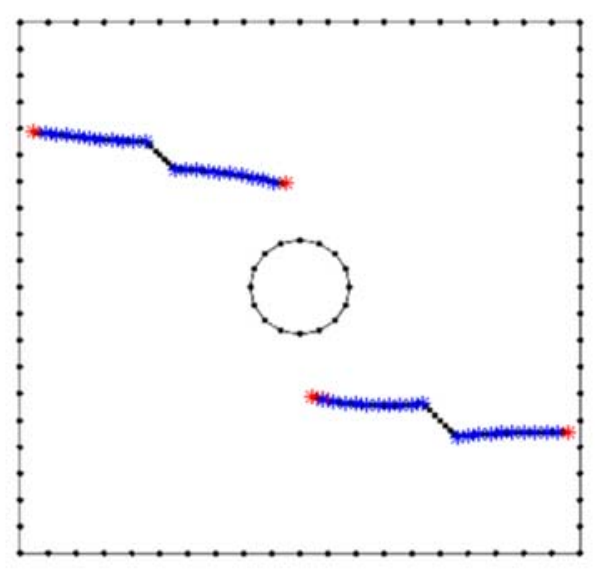

(a)

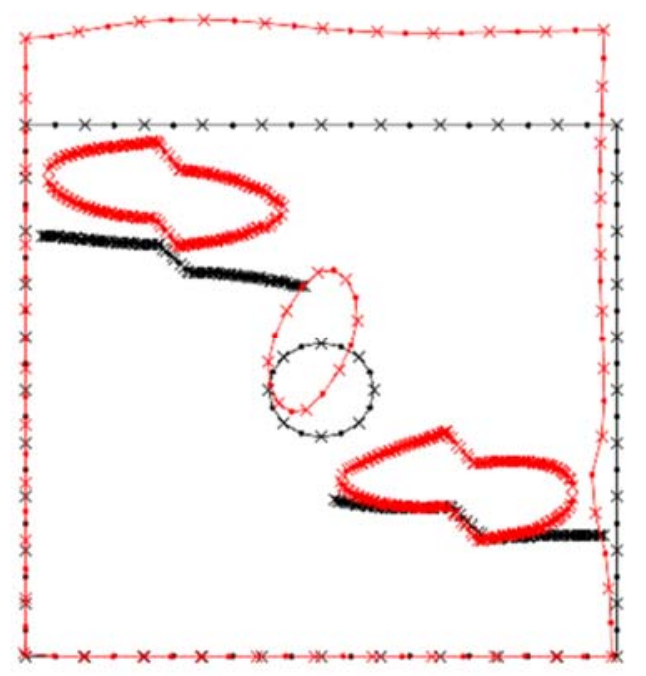

(b)

Figure 10: Micro model results; a) crack propagation; b) deformed mesh.

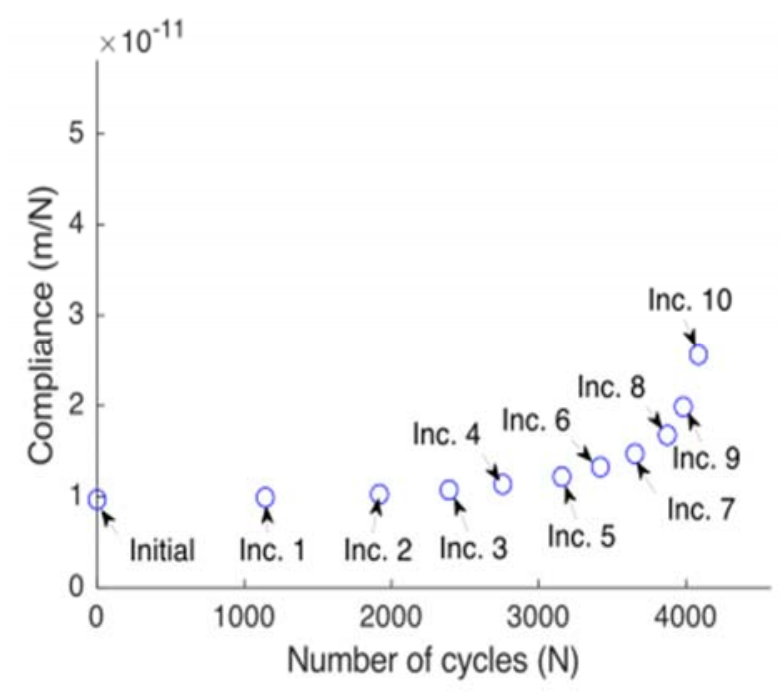

(a)

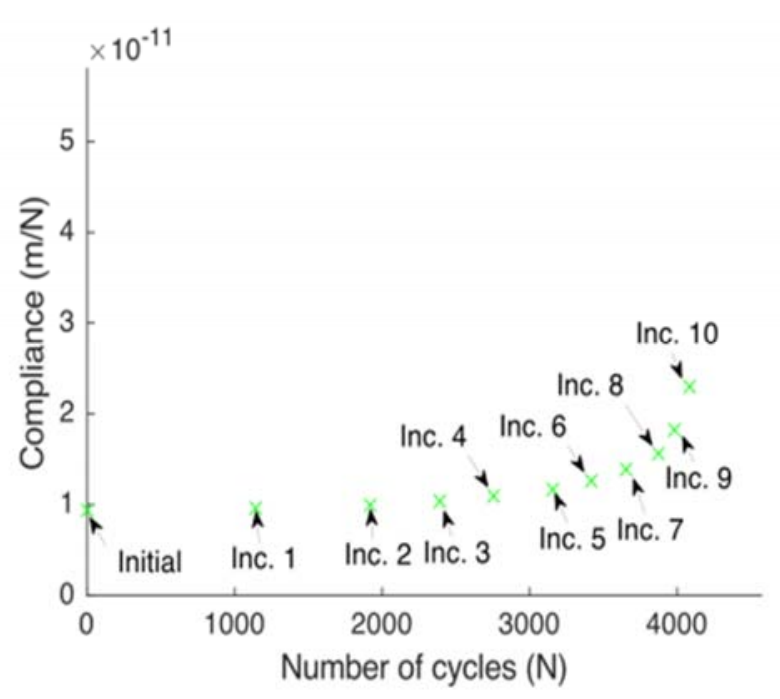

(b)

Figure 11: Relation number of cycles versus compliance points for each increment; (a) Upper edge; (b) Right edge. 


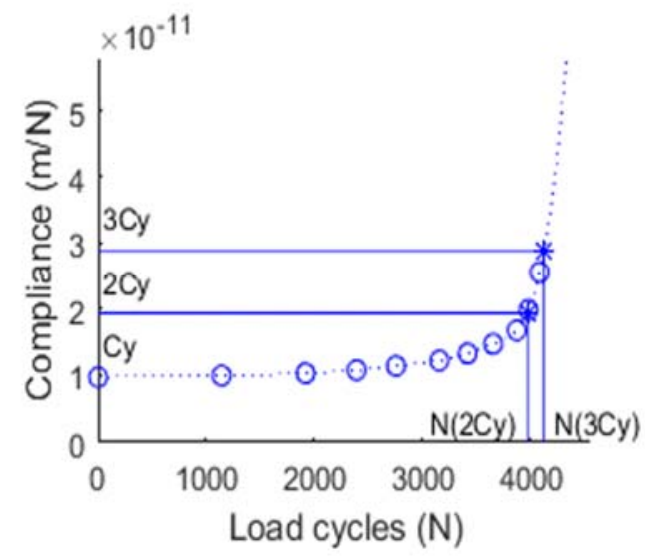

(a)

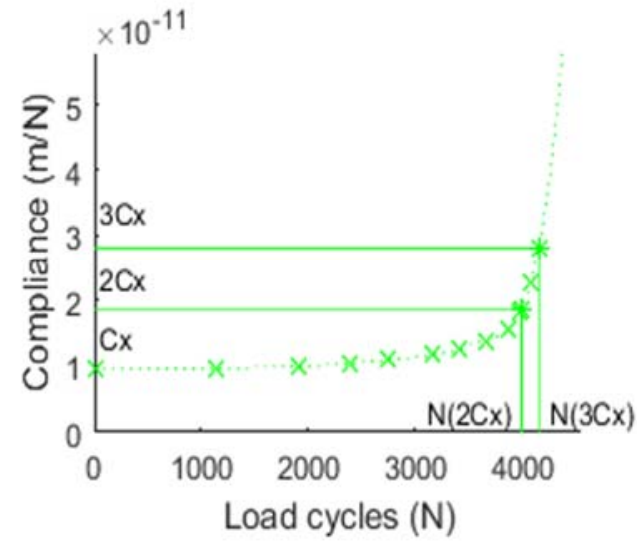

(b)

Figure 12: Load cycles versus compliance curves; (a) Upper edge; (b) Right edge.
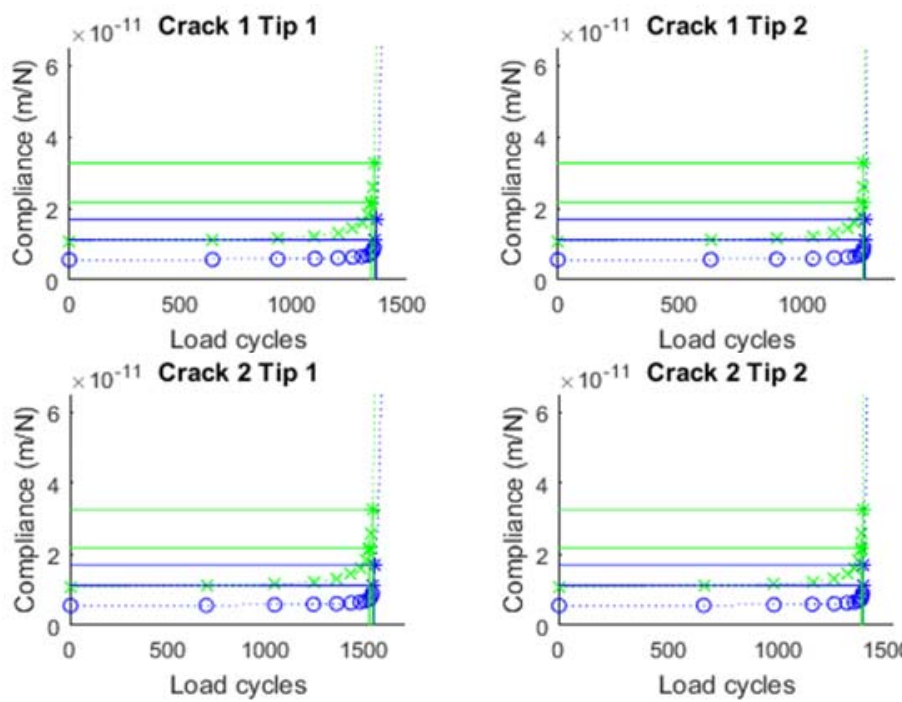

- Cy Upper edge

$\times$ Cx Right edge

* Point 2Cy (Upper edge)

* Point 2Cx (Right edge)

* Point 3Cy (Upper edge)

* Point 3Cx (Right edge)

Figure 13: Load cycles versus compliance curves for all crack tips.

\section{Application}

$\mathrm{T}$ his section presents two applications based on the model presented in [57], in order to demonstrate the accuracy of the proposed methodology, as well as to validate the robustness of the BemCracker2D program as part of it For simplification purposes, the results of the macro and micro models regarding the mesh, stress field and deformed shape will not be shown, but only those related to the stress peak location, number of cycles, compliance and the respective curves. In both applications, $P$ and $Q$ represent the normal and shear loads, respectively; $r$ is the radius of the central hole; $L 1$ and $L 2$ are the size of the top and bottom cracks, respectively.

\section{A1 Application}

Tab. 1 presents the macro and micro values for the first application, whose external request produces the location of the voltage peak as illustrated in Fig. 14. Next, the algorithm positions the micro element at the peak composed of the stresses arranged in Tab. 2 and executes the fatigue test to evaluate the respective number of cycles at each propagation crack until the last increment before reaching an edge. Finally, at each increment, there are the points for the construction of the fatigue life curve $(\mathrm{N})$ versus the average compliance of the edges, as illustrated in Fig. 15. Thus, as this element was executed at the point of stress peak, these curves correspond to the worst situation, the $N_{3 C}$ minimums. 
For this application, the values of $C=5 \mathrm{e}-11$ and $m=2.5$ of the Paris's constants were considered to calculate the number of cycles. However, by varying these values, the number of cycles also varies, thus making it possible to create the curve that relates the variables $C$ and $m$ with the number of cycles, as will be shown below.

\section{Curve $\mathrm{N}(C, \mathrm{~m})$ for $A 1$ Application}

Adopting $C$ and $m$ from Paris's Law in the form of a grid in the domain $C=[5 \mathrm{e}-11,9.5 \mathrm{e}-11]$ and $m=[2.7,3.2]$, the points that relate them to the number of cycles are obtained, as illustrated in Fig. 16.

\begin{tabular}{cc|cc}
\hline \multicolumn{2}{c|}{ Macro variables } & \multicolumn{2}{c}{ Micro variables } \\
$\mathrm{P}(\mathrm{MPa})$ & 360.47 & $\mathrm{r}(\mathrm{cm})$ & 0.089 \\
$\mathrm{Q}(\mathrm{MPa})$ & 92.78 & $\mathrm{~L} 1(\mathrm{~cm})$ & 0.074 \\
& & $\mathrm{~L} 2(\mathrm{~cm})$ & 0.086 \\
\hline
\end{tabular}

Table 1: Variable values for A1 application.
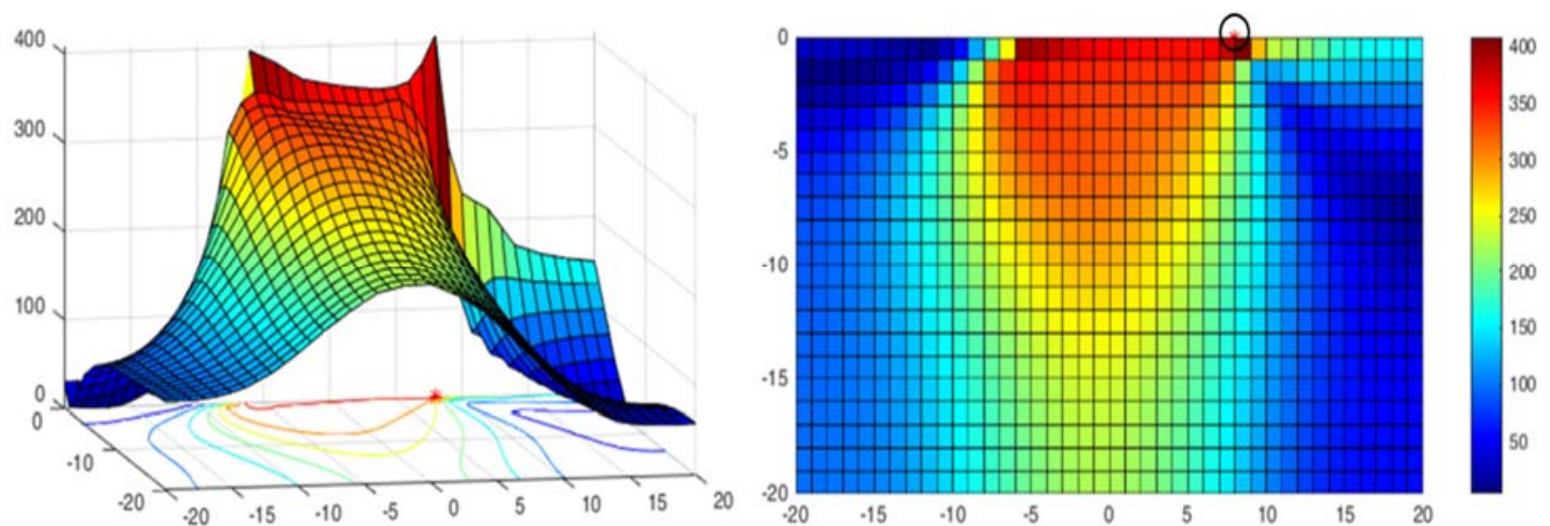

Figure 14: Peak stress location.

\begin{tabular}{cc} 
& Stresses \\
\hline$\sigma_{\mathrm{x}}(\mathrm{MPa})$ & -30.66 \\
$\sigma_{\mathrm{y}}(\mathrm{MPa})$ & 360.00 \\
$\tau(\mathrm{MPa})$ & 92.00 \\
\hline
\end{tabular}

Table 2: Peak stresses values for A1 application.

Next, through the interpolation of the points obtained in Fig. 16, the surface that represents the function that relates $C$ in with the number of cycles is obtained, Fig. 17. With that, to find the values of the constants that carry the number of minimum cycles to the design value, the intersection between the relationship curves with the surface of the required number of cycles must be found. For example, considering the number of cycles defined in the project as $1 \mathrm{e}+04$, the intersection is shown in the red line, as shown in Fig. 18 (a). In Fig. 18 (b), in the $C \times m$ plane, the curve that shows the parameters $C$ and $m$ that the material must have for the number of cycles requested by the user is obtained, thus originating the graph in Fig. 19 showing that it supports 10,000 cycles. 

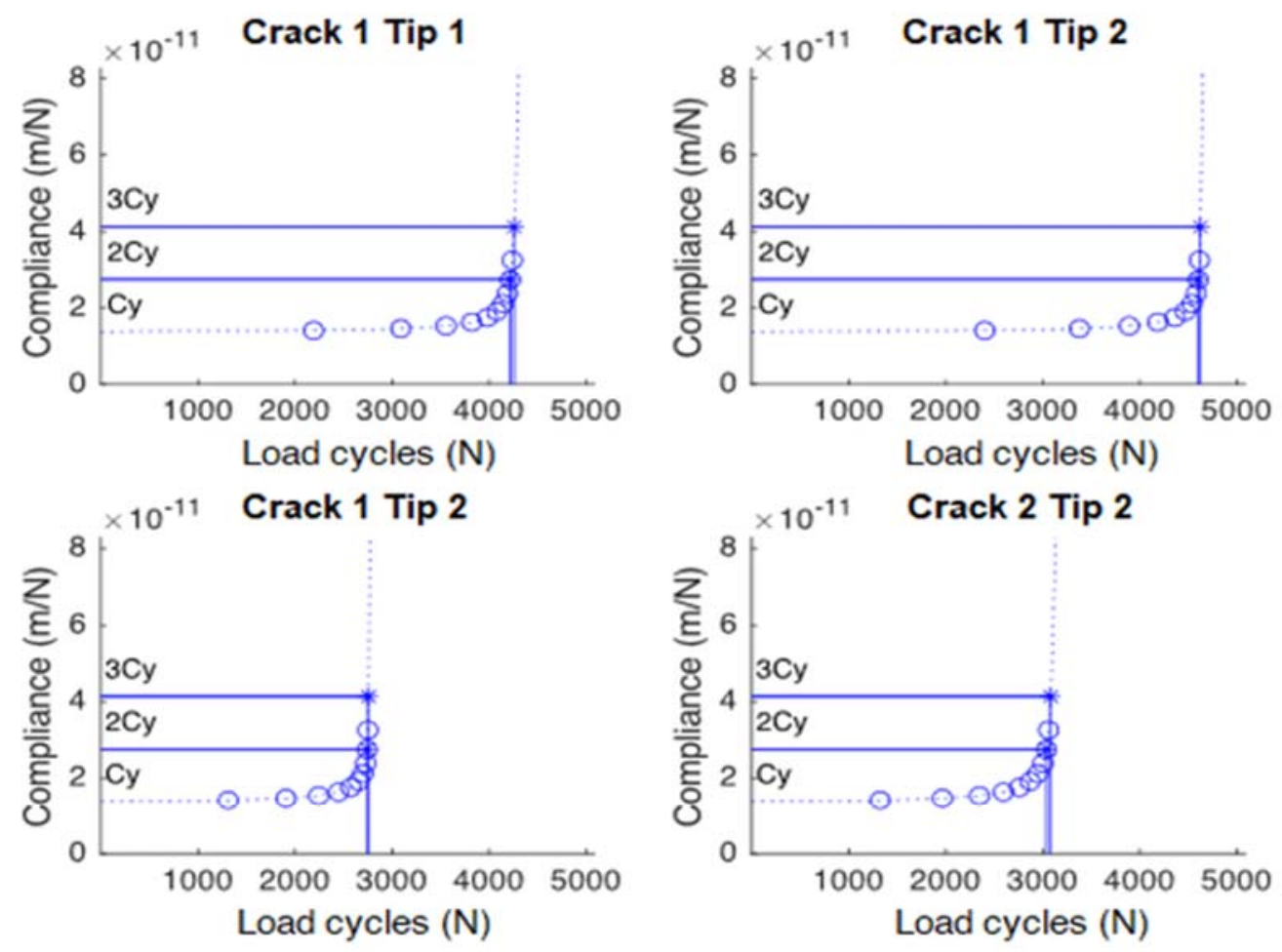

\begin{tabular}{|c|c|c|c|c|c|}
\hline & Cy & $2 C y$ & $N(2 C y)$ & $3 C y$ & $N(3 C y)$ \\
\hline C1 T1 & $1.3788 \mathrm{e}-11$ & $2.7575 e-11$ & $4.2173 e+03$ & $4.1363 \mathrm{e}-11$ & $4.2574 e+03$ \\
\hline $\mathrm{C} 1 \mathrm{~T} 2$ & $1.3788 \mathrm{e}-11$ & $2.7575 e-11$ & $4.6025 e+03$ & $4.1363 \mathrm{e}-11$ & $4.6230 \mathrm{e}+03$ \\
\hline $\mathrm{C} 2 \mathrm{~T} 1$ & $1.3788 \mathrm{e}-11$ & $2.7575 e-11$ & $2.7431 e+03$ & $4.1363 e-11$ & $2.7561 e+03$ \\
\hline $\mathrm{C} 2 \mathrm{~T} 2$ & $1.3788 \mathrm{e}-11$ & $2.7575 e-11$ & $3.0372 \mathrm{e}+03$ & $4.1363 \mathrm{e}-11$ & $3.0801 e+03$ \\
\hline
\end{tabular}

Figure 15: Load cycles versus compliance curves.

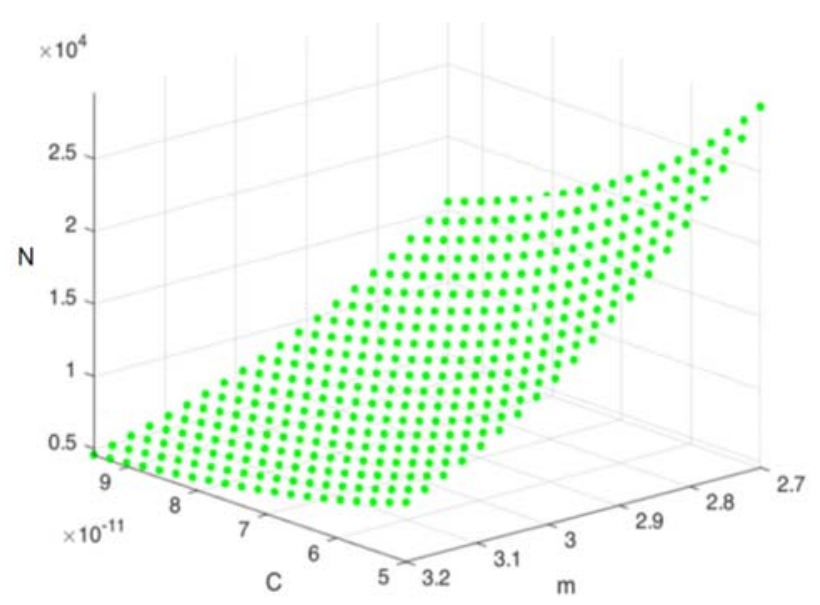

Figure 16: Relation $(C, m)$ versus load cycles $(\mathrm{N})$ points.

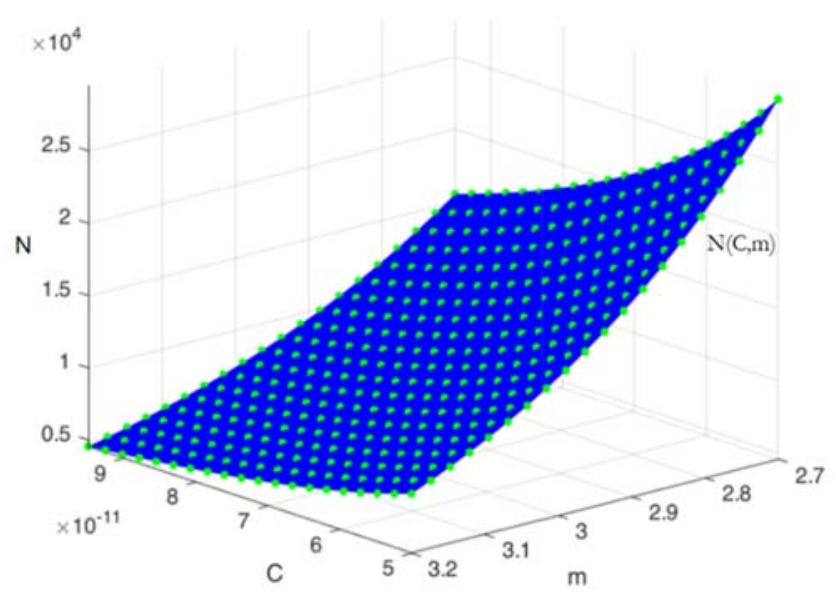

Figure 17: Relation $(C, m)$ versus load cycles $(\mathrm{N})$ curve. 


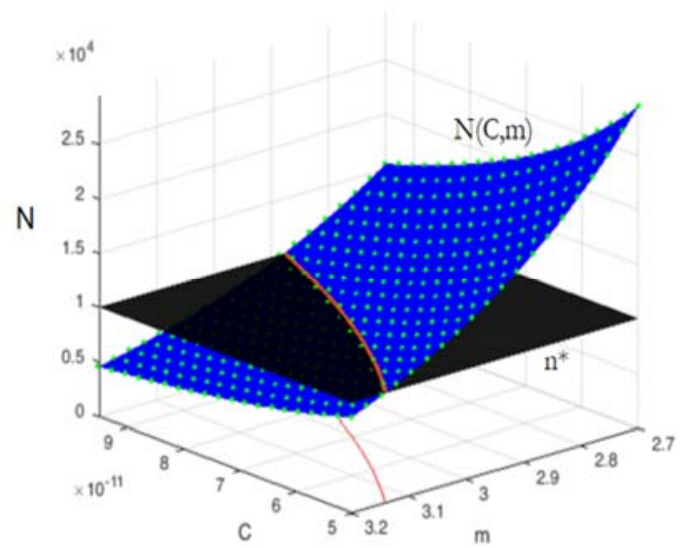

(a)

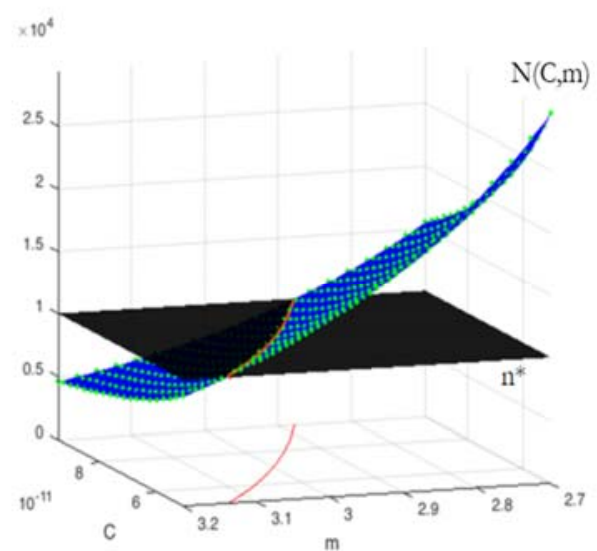

(b)

Figure 18: Intersection between $\mathrm{N}(C, m)$ curve versus design load cycles curve $\left(\mathrm{n}^{*}\right)$.

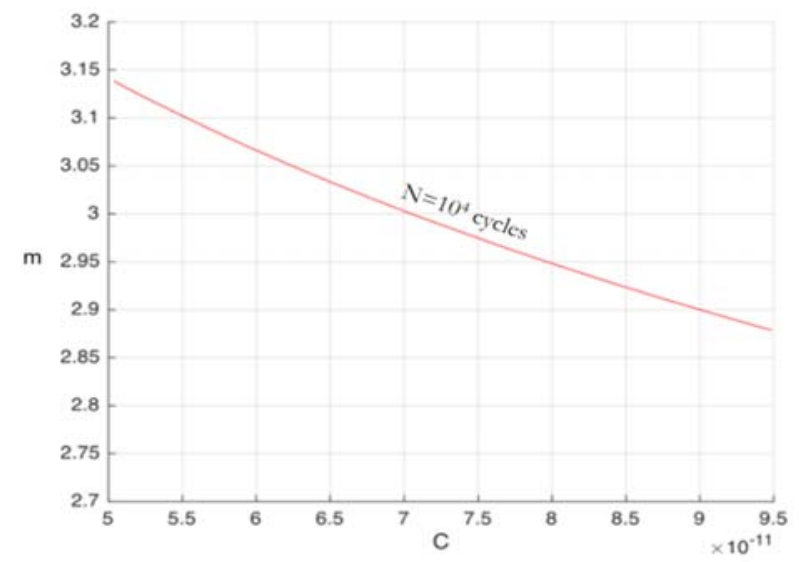

Figure 19: Relation $(C, m)$ with 1e+04 design number cycles.

Furthermore, by modifying the value of the number of design cycles $n^{*}$ (black color surface of Fig. 18), it is possible to obtain the variation of $C$ and $m$ for each value of $n^{*}$ requested in design, as shown in Fig. 20.

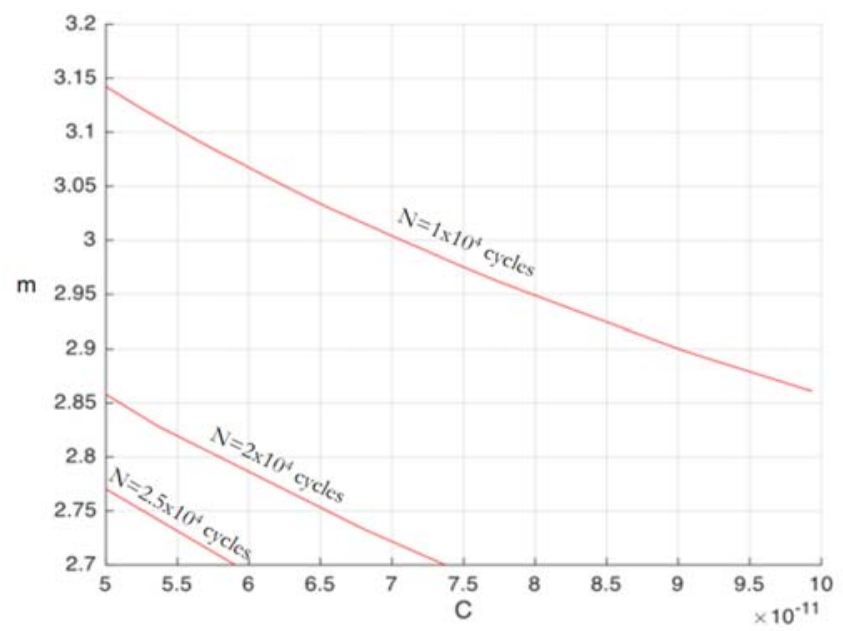

Figure 20: Relation $(C, m)$ resulting in $1 \mathrm{e}+04,2 \mathrm{e}+04,2.5 \mathrm{e}+04$ design number cycles. 


\section{A2 Application}

Tab. 3 presents the macro and micro values for the second application, while the location of the stress peak is seen in Fig. 21. The stress peak is displayed in Tab. 4 and, finally, at each increment, there are the points for the construction of the fatigue life curve $(N)$ versus average compliance of the edges, as illustrated in Fig. 22.

\begin{tabular}{lccc}
\hline \multicolumn{2}{c}{ Macro variables } & \multicolumn{2}{c}{ Micro variables } \\
$\mathrm{P}(\mathrm{MPa})$ & 343.58 & $\mathrm{r}(\mathrm{cm})$ & 0.112 \\
$\mathrm{Q}(\mathrm{MPa})$ & 90.70 & $\mathrm{~L} 1(\mathrm{~cm})$ & 0.081 \\
& & $\mathrm{~L} 2(\mathrm{~cm})$ & 0.093 \\
\hline
\end{tabular}

Table 3: Variable values for A2 application.
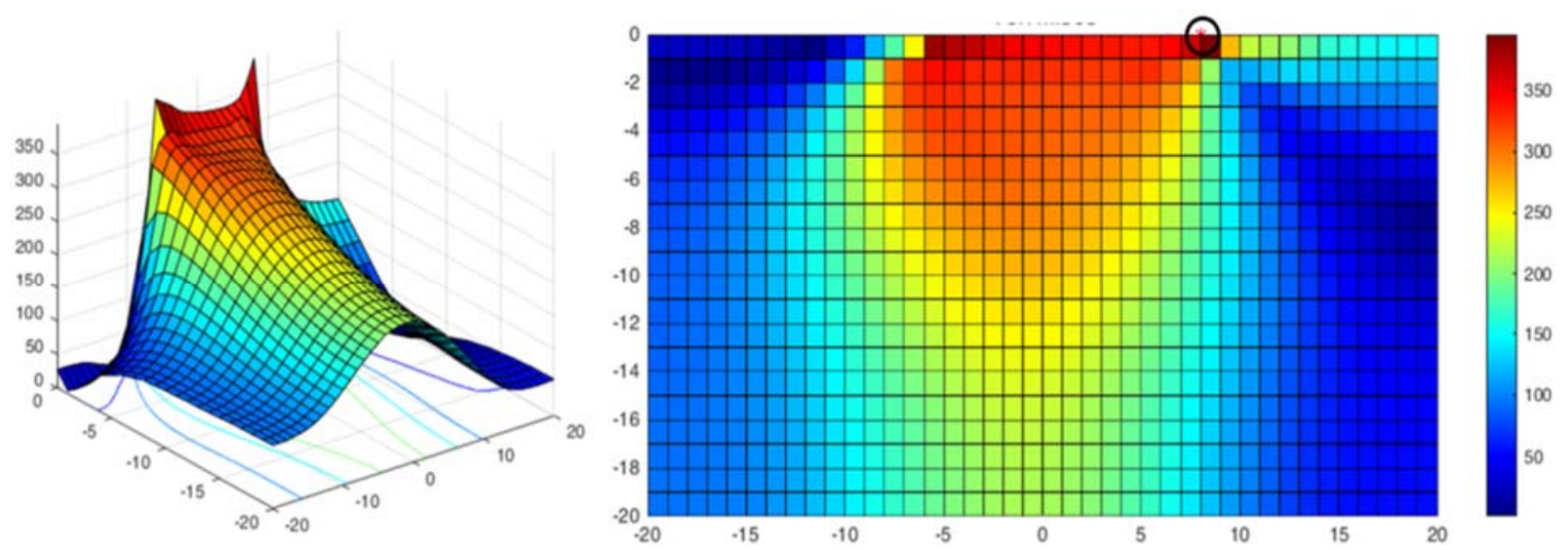

Figure 21: Peak stress location.

\begin{tabular}{cc}
\hline \multicolumn{2}{c}{ Stresses } \\
$\sigma_{\mathrm{x}}(\mathrm{MPa})$ & -36.06 \\
$\sigma_{\mathrm{y}}(\mathrm{MPa})$ & 343.58 \\
$\tau(\mathrm{MPa})$ & 90.70 \\
\hline
\end{tabular}

Table 4: Peak stress values for A2 application.

\section{Curve $N(C, m)$ for A2 Application}

Fig. 23 shows the domain $C=[5 \mathrm{e}-11,9.5 \mathrm{e}-11]$ and $m=[2.7,3.2]$ relating them to the number of cycles.

Fig. 24 (a) illustrates the surface that represents the function relating $C$ and $m$ with the number of cycles. Thus, considering the number of cycles defined in the project as $1 \mathrm{e}+04$, for example, the intersection is shown in the red line. In Fig. 24 (b), in the $C \times m$ plane, the curve that shows the parameters $C$ and $m$ that the material must have for the number of cycles requested by the user is obtained, thus originating the graph in Fig. 25, showing that it supports 10,000 cycles. Furthermore, by modifying the value of the number of design cycles $n^{*}$ (black color surface of Fig. 24), it is possible to obtain the variation of $C$ and $m$ for each value of $n^{*}$ requested in design, as shown in Fig. 26. 

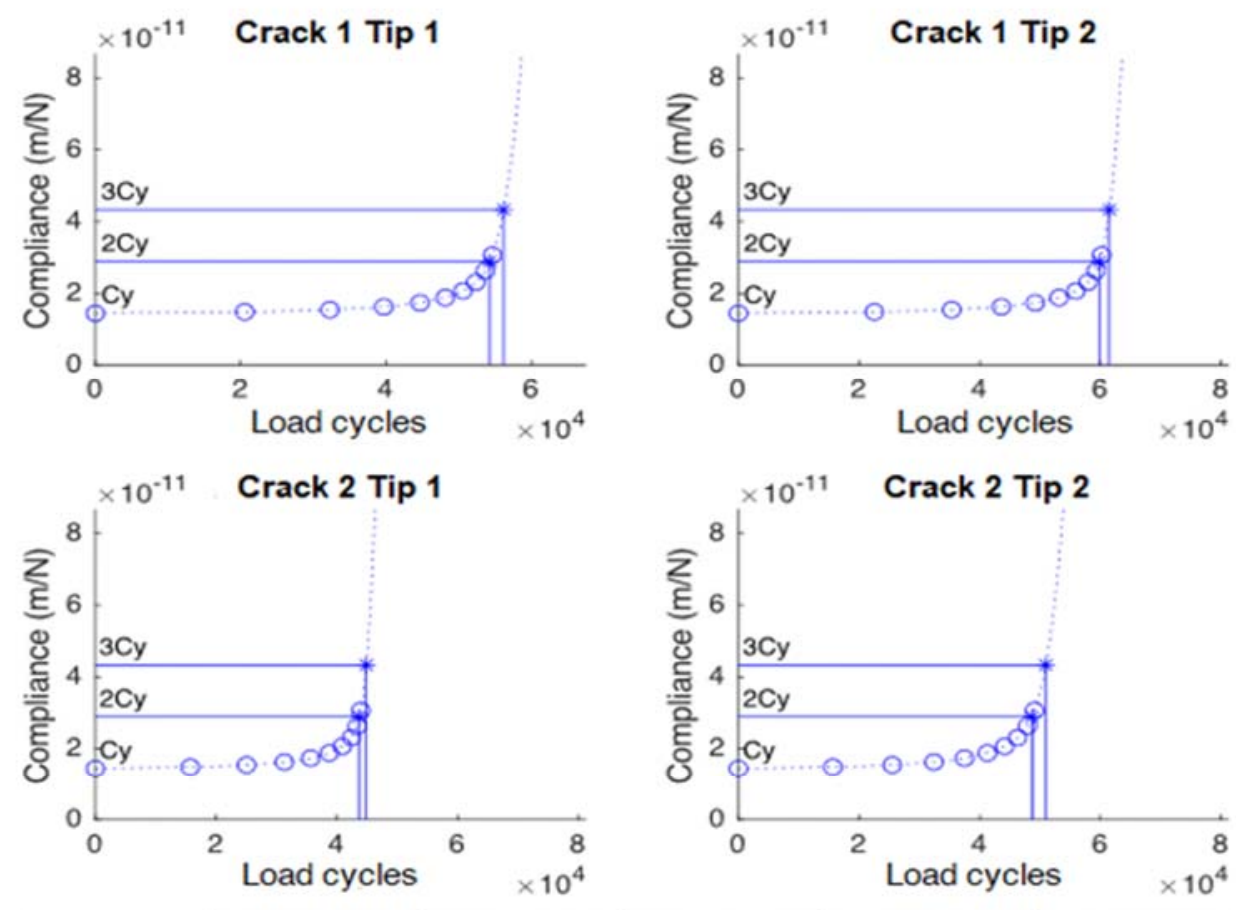

\begin{tabular}{|c|c|c|c|c|c|}
\hline & Cy & $2 C y$ & $N(2 C y)$ & $3 C y$ & $N(3 C y)$ \\
\hline C1 T1 & $1.4445 \mathrm{e}-11$ & $2.8890 e-11$ & $5.4301 e+04$ & $4.3335 e-11$ & $5.6193 e+04$ \\
\hline $\mathrm{C} 1 \mathrm{~T} 2$ & $1.4445 \mathrm{e}-11$ & $2.8890 \mathrm{e}-11$ & $5.9865 e+04$ & $4.3335 e-11$ & $6.1490 e+04$ \\
\hline C2 T1 & $1.4445 e-11$ & $2.8890 \mathrm{e}-11$ & $4.3767 e+04$ & $4.3335 e-11$ & $4.4879 e+04$ \\
\hline $\mathrm{C} 2 \mathrm{~T} 2$ & $1.4445 e-11$ & $2.8890 \mathrm{e}-11$ & $4.8681 e+04$ & $4.3335 e-11$ & $5.0924 e+04$ \\
\hline
\end{tabular}

Figure 22: Load cycles versus compliance curves.

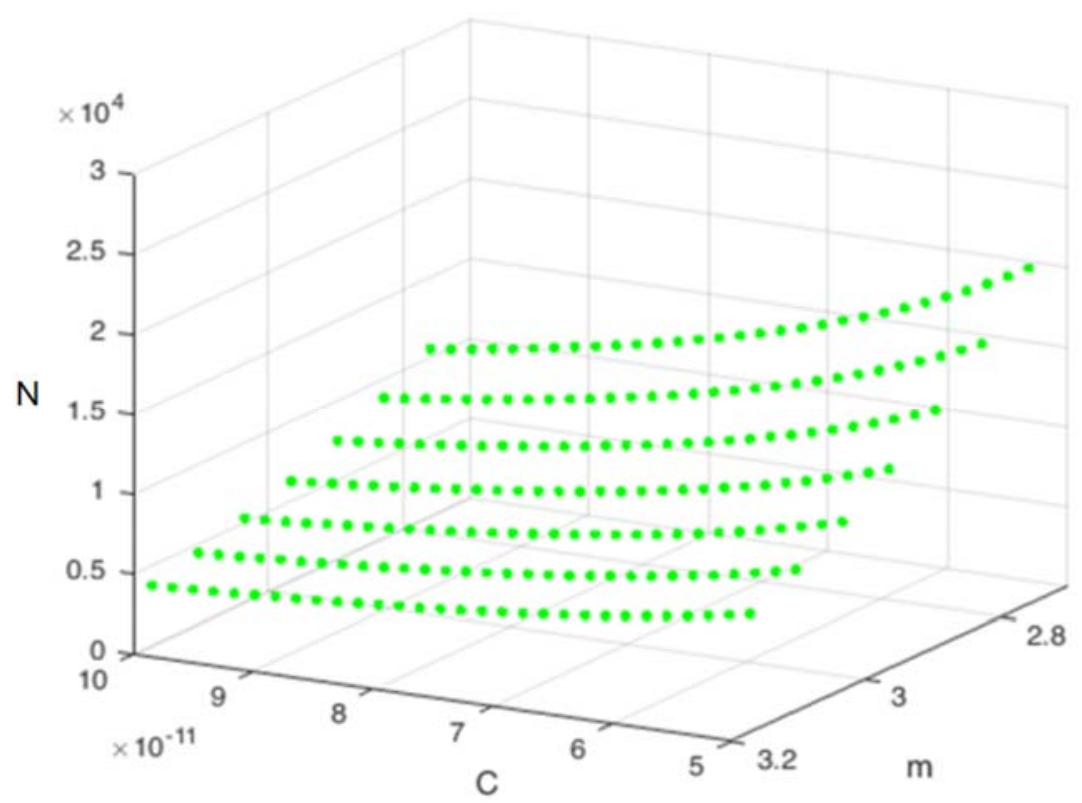

Figure 23: Relation $(C, m)$ versus load cycles $(\mathrm{N})$ points. 


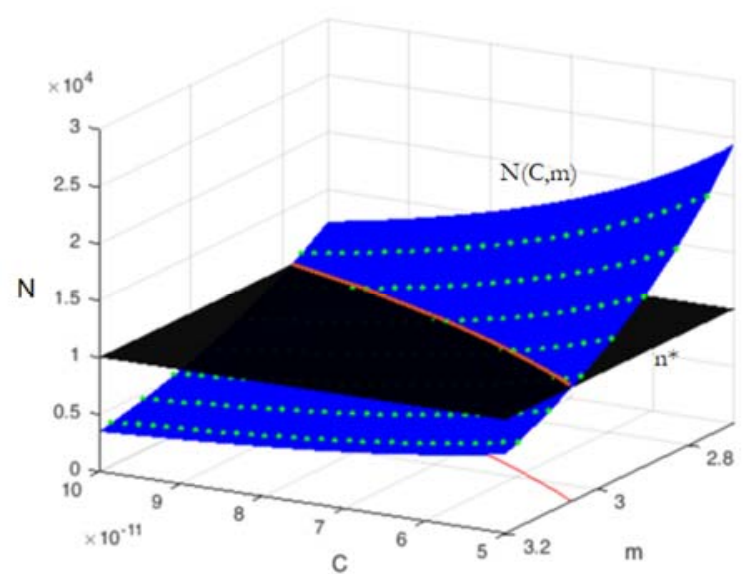

(a)

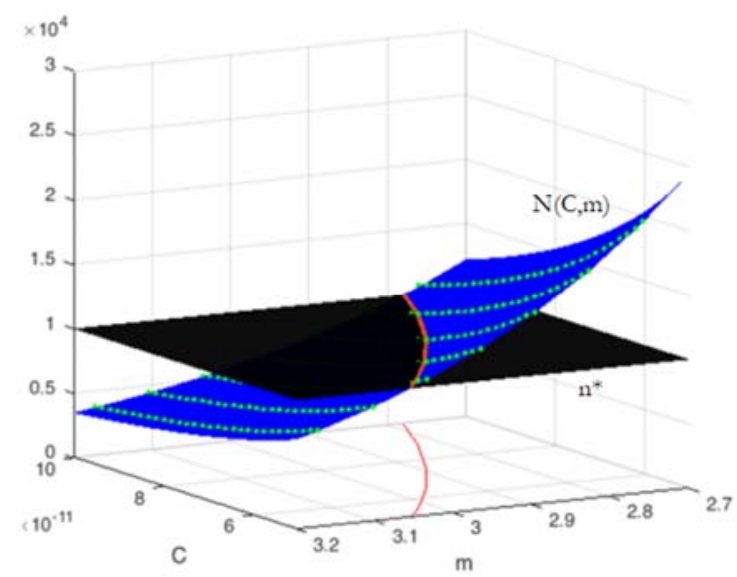

(b)

Figure 24: Intersection between $N(C, m)$ curve versus design load cycles curve $\left(n^{*}\right)$.

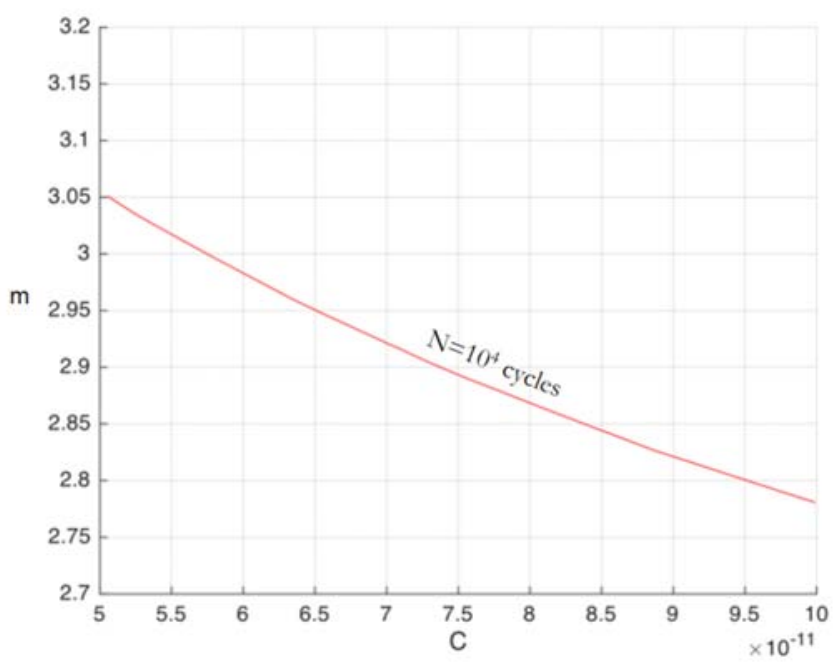

Figure 25: Relation $(C, m)$ with 1e+04 design number cycles.

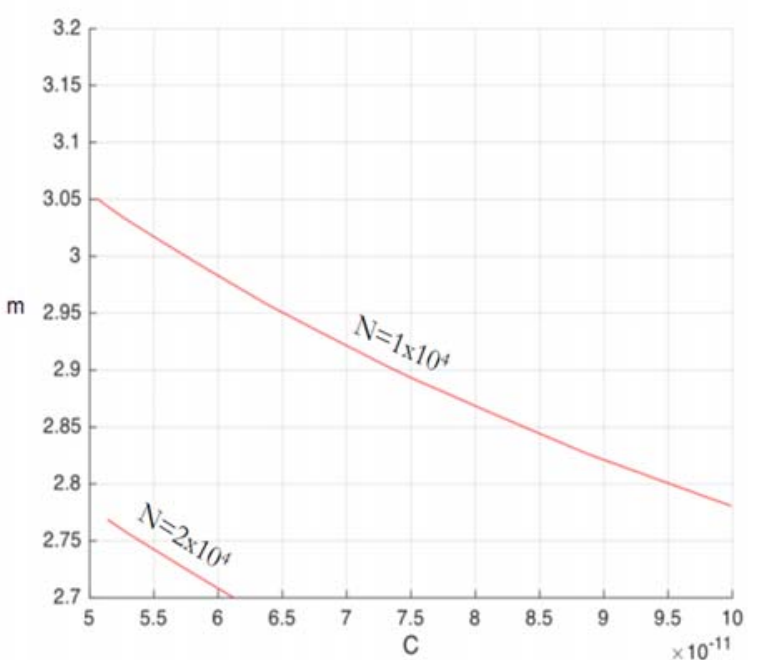

Figure 26: Relation $(C, m)$ that results $1 \mathrm{e}+04,2 \mathrm{e}+04$ design number cycles.

\begin{tabular}{ccc}
\hline Application/variables & A1 & A2 \\
P (MPa) & 360.47 & 343.58 \\
Q (MPa) & 92.78 & 90.70 \\
r (cm) & 0.089 & 0.112 \\
L1 (cm) & 0.074 & 0.081 \\
L2 (cm) & 0.086 & 0.093 \\
\hline
\end{tabular}

Table 5: Comparison between A1 and A2 Applications.

\section{Comparisons between $A 1$ and $A 2$ applications}

Here, the curves $C$ and $m$ between applications A1 and A2 are compared. Tab. 5 shows the values of the variables for each application and, in Fig. 27, the respective curves are illustrated. In this table, one can observe the difference in the choice of Paris' values when we change the input variables $P, Q, r, L 1, L 2$. 


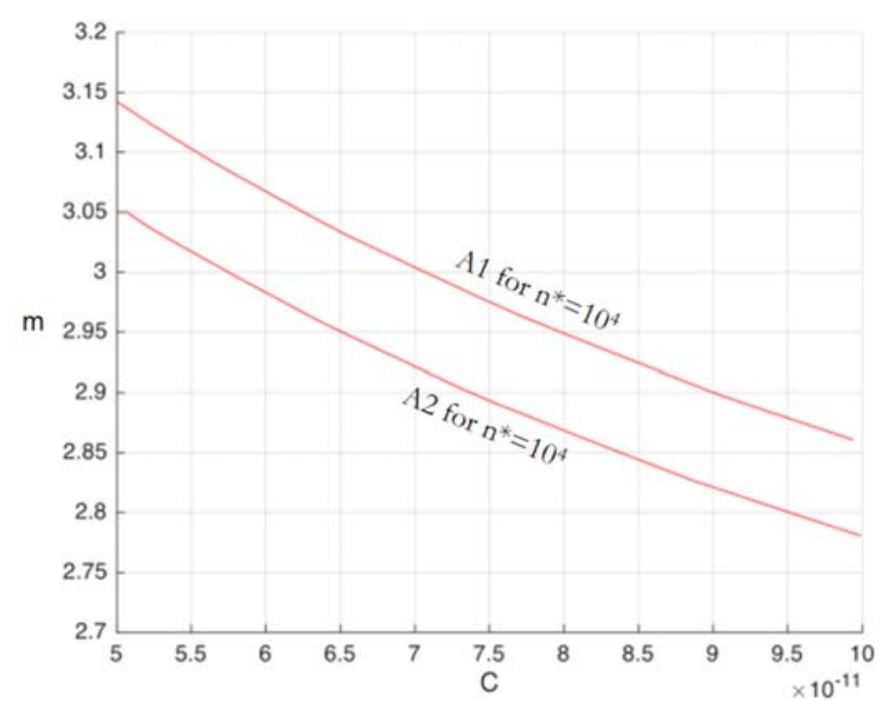

Figure 27: Comparison between A1 and A2 $(C, m)$ curves for 1e+04 design load cycles.

\section{FINAL REMARKS}

$\mathrm{T}$ he proposed methodology is an alternative to the classical damage tolerance analysis in which the evaluation of damage is done through the critical crack size. In this research, the critical size is disregarded and compliance is evaluated as the defining variable of instability. The use of the Boundary Elements Method (BEM), as a numerical method, has been essential because of its flexibility, precision and mesh simplicity. With the BEM, the proposed numerical fatigue life technique was programmed without complex re-meshing processing as in the FEM. The suggested formulation was useful to evaluate both the location of the stress peak and the compliance of the edges of the local analysis elements. This research presents the relationship between the Paris' constants $(C$ and $m$ ) and damage tolerance, through curves relating the Paris' constants to the desired number of cycles. A function is presented with the parametric data of $\mathrm{C}$ and $\mathrm{m}$ related to the desired number of cycles in a conservative way to avoid instability. The automation of the technique presented in this research with the use of the computer programs BEMLAB2D and BemCracker2D enable the analysis of fatigue tolerance in two-dimensional geometries and under plain stress or strain. The programs allow damage analyses throughout the parametric data of $\mathrm{C}$ and $\mathrm{m}$ of Paris' law to ensure damage tolerance and avoid the undesired Limit State. This research is an initial contribution and more work is needed and encouraged.

\section{ACKNOWLEDGMENT}

7 he authors are grateful to the Brazilian National Research Council (CNPq) and to the Brazilian Coordination for the Improvement of Higher Education Personnel (CAPES) for the supporting funds for this research. The authors also thank the Graduate Programme in Structural Engineering and Civil Construction in the Department of Civil and Environmental Engineering at the University of Brasilia.

\section{REFERENCES}

[1] NTSB, N.T.S.B. (1989). Aircraft Accident Report, Aloha Airlines, Flight 243, Boeing 737-200, N73711, Near Maui, Hawaii, April 28, 1988.

[2] Wanhill, R., Molent, L., Barter, S. (2016). Milestone Case Histories in Aircraft Structural Integrity. Reference Module in Materials Science and Materials Engineering, Elsevier.

[3] Sanford, R.J. (2002). Principles of Fracture Mechanics.

[4] Palmberg, B., Blom, A.F., Eggwertz, S. (1987). Probabilistic damage tolerance analysis of aircraft structures. Probabilistic fracture mechanics and reliability, Dordrecht, Springer Netherlands, pp. 47-130. 
[5] Wanhill, R. (1994). Flight simulation fatigue crack growth testing of aluminium alloys Specific issues and guidelines, Int. J. Fatigue, 16(2), pp. 99-110, DOI: 10.1016/0142-1123(94)90100-7.

[6] Wanhill, R. (1994). Status and prospects for aluminium-lithium alloys in aircraft structures, Int. J. Fatigue, 16(1), pp. 3-20, DOI: 10.1016/0142-1123(94)90441-3.

[7] Newman, J.C. (1998). The merging of fatigue and fracture mechanics concepts: a historical perspective, Prog. Aerosp. Sci., 34(5-6), pp. 347-390, DOI: 10.1016/S0376-0421(98)00006-2.

[8] Newman, J. (1999). Fatigue-life prediction methodology using small-crack theory, Int. J. Fatigue, 21(2), pp. 109119, DOI: $10.1016 /$ S0142-1123(98)00058-9.

[9] Schijve, J. (2009). Fatigue damage in aircraft structures, not wanted, but tolerated?, Int. J. Fatigue, 31(6), pp. 9981011, DOI: 10.1016/j.ijfatigue.2008.05.016.

[10] Barter, S., Molent, L., Goldsmith, N., Jones, R. (2005). An experimental evaluation of fatigue crack growth, Eng. Fail. Anal., 12(1), pp. 99-128, DOI: 10.1016/j.engfailanal.2004.04.002.

[11] Molent, L., Barter, S.A. (2010). The lead fatigue crack concept for aircraft structural integrity, Procedia Eng., 2(1), pp. 363-377, DOI: 10.1016/j.proeng.2010.03.041.

[12] Barter, S.A., Molent, L., Wanhill, R.J.H. (2012). Typical fatigue-initiating discontinuities in metallic aircraft structures, Int. J. Fatigue, 41, pp. 11-22, DOI: 10.1016/j.ijfatigue.2011.10.017.

[13] Molent, L., Forrester, C. (2017). The lead crack concept applied to defect growth in aircraft composite structures, Compos. Struct., 166, pp. 22-26, DOI: 10.1016/j.compstruct.2016.12.076.

[14] Chowdhury, P., Sehitoglu, H., Rateick, R. (2018). Damage tolerance of carbon-carbon composites in aerospace application, Carbon N. Y., 126, pp. 382-393, DOI: 10.1016/j.carbon.2017.10.019.

[15] Chowdhury, N.M., Chiu, W.K., Wang, J., Chang, P. (2016). Experimental and finite element studies of bolted, bonded and hybrid step lap joints of thick carbon fibre/epoxy panels used in aircraft structures, Compos. Part B Eng., 100, pp. 68-77, DOI: 10.1016/j.compositesb.2016.06.061.

[16] Pegorin, F., Pingkarawat, K., Mouritz, A.P. (2015). Comparative study of the mode I and mode II delamination fatigue properties of z-pinned aircraft composites, Mater. Des., 65, pp. 139-146,

DOI: 10.1016/j.matdes.2014.08.072.

[17] Smith, L., Pilarczyk, R., Feiger, J. (2016). Validation Testing and Analysis of Cracked-Hole Continuing Damage Solutions, Mater. Perform. Charact., 5(3), pp. mpc20150055, DOI: 10.1520/MPC20150055.

[18] Sonmez, F.O. (2007). Shape optimization of 2D structures using simulated annealing, Comput. Methods Appl. Mech. Eng., 196(35-36), pp. 3279-3799, DOI: 10.1016/j.cma.2007.01.019.

[19] Chintapalli, S., Elsayed, M.S.A., Sedaghati, R., Abdo, M. (2010). The development of a preliminary structural design optimization method of an aircraft wing-box skin-stringer panels, Aerosp. Sci. Technol., 14(3), pp. 188198, DOI: $10.1016 /$ j.ast.2009.12.007.

[20] Gorelik, M. (2017). Additive manufacturing in the context of structural integrity, Int. J. Fatigue, 94, pp. 168-177, DOI: 10.1016/j.ijfatigue.2016.07.005.

[21] Ciavarella, M., Papangelo, A. (2018). On the distribution and scatter of fatigue lives obtained by integration of crack growth curves: Does initial crack size distribution matter?, Eng. Fract. Mech., 191, pp. 111-124, DOI: $10.1016 /$ j.engfracmech.2018.01.019.

[22] Carta, F., Pirondi, A. (2011). Damage tolerance analysis of aircraft reinforced panels, Frat. Ed Integrità Strutt., 5(16), pp. 34-42, DOI: 10.3221/IGF-ESIS.16.04.

[23] Srivastava, A.K., Arora, P.K., Kumar, H. (2016). Numerical and experiment fracture modeling for multiple cracks of a finite aluminum plate, Int. J. Mech. Sci., 110, pp. 1-13, DOI: 10.1016/j.ijmecsci.2016.02.010.

[24] Wen, P.H., Aliabadi, M.H., Young, A. (2004). Crack growth analysis for multi-layered airframe structures by boundary element method, Eng. Fract. Mech., 71(4-6), pp. 619-631, DOI: 10.1016/S0013-7944(03)00021-3.

[25] Salgado, N.K., Aliabadi, M.H. (1997). The analysis of mechanically fastened repairs and lap joints, Fatigue Fract. Eng. Mater. Struct., 20(4), pp. 583-593, DOI: 10.1111/j.1460-2695.1997.tb00290.x.

[26] Ju, J., You, X. (2013). Dynamic fracture analysis technique of aircraft fuselage containing damage subjected to blast, Math. Comput. Model., 58(3-4), pp. 627-633, DOI: 10.1016/j.mcm.2011.10.044.

[27] Portela, A., Aliabadi, M.H., Rooke, D.P. (1992). The dual boundary element method: Effective implementation for crack problems, Int. J. Numer. Methods Eng., 33(6), pp. 1269-1287, DOI: 10.1002/nme.1620330611.

[28] Portela, A., Aliabadi, M.H., Rooke, D.P. (1992). Dual boundary element analysis of cracked plates: singularity subtraction technique, Int. J. Fract., 55(1), pp. 17-28, DOI: 10.1007/BF00018030.

[29] Blandford, G.E., Ingraffea, A.R., Liggett, J.A. (1981). Two-dimensional stress intensity factor computations using the boundary element method, Int. J. Numer. Methods Eng., 17(3), pp. 387-404, DOI: 10.1002/nme.1620170308. 
[30] Citarella, R. (2011). MSD crack propagation by DBEM on a repaired aeronautic panel, Adv. Eng. Softw., 42(10), pp. 887-901, DOI: 10.1016/j.advengsoft.2011.02.014.

[31] Citarella, R., Carlone, P., Sepe, R., Lepore, M. (2016). DBEM crack propagation in friction stir welded aluminum joints, Adv. Eng. Softw., 101, pp. 50-59, DOI: 10.1016/j.advengsoft.2015.12.002.

[32] Price, R.J., Trevelyan, J. (2014). Boundary element simulation of fatigue crack growth in multi-site damage, Eng. Anal. Bound. Elem., 43, pp. 67-75, DOI: 10.1016/j.enganabound.2014.03.002.

[33] Morse, L., Khodaei, Z.S., Aliabadi, M.H. (2017). Multi-Fidelity Modeling-Based Structural Reliability Analysis with the Boundary Element Method, J. Multiscale Model., 08(03n04), pp. 1740001, DOI: 10.1142/S1756973717400017.

[34] Huang, X., Aliabadi, M.H., Khodaei, Z.S. (2014). Fatigue Crack Growth Reliability Analysis by Stochastic Boundary Element Method, C. Model. Eng. Sci., 102(4), pp. 291-330, DOI: 10.3970/cmes.2014.102.291.

[35] Oliveira, T.A.A., Gomes, G., Evangelista Jr, F. (2019). Multiscale aircraft fuselage fatigue analysis by the dual boundary element method, Eng. Anal. Bound. Elem., 104, pp. 107-119,

DOI: 10.1016/j.enganabound.2019.03.032.

[36] Lopez, I., Sarigul-Klijn, N. (2010). A review of uncertainty in flight vehicle structural damage monitoring, diagnosis and control: Challenges and opportunities, Prog. Aerosp. Sci., 46(7), pp. 247-273,

DOI: $10.1016 /$ j.paerosci.2010.03.003.

[37] Paris, P., Erdogan, F. (1963). A Critical Analysis of Crack Propagation Laws, J. Basic Eng., 85(4), pp. 528-533, DOI: $10.1115 / 1.3656900$.

[38] Pyo, C.R., Okada, H., Atluri, S.N. (1995). An elastic-plastic finite element alternating method for analyzing widespread fatigue damage in aircraft structures, Comput. Mech., 16(1), pp. 62-68, DOI: 10.1007/BF00369886.

[39] Jeong, D.Y., Tong, P. (1997). Onset of multiple site damage and widespread fatigue damage in aging airplanes., Int. J. Fract., 85, pp. 185-200, DOI: 10.1023/A:1007452712730.

[40] Platz, R., Stapp, C., Hanselka, H. (2011). Statistical approach to evaluating reduction of active crack propagation in aluminum panels with piezoelectric actuator patches, Smart Mater. Struct., 20(8), pp. 085009,

DOI: $10.1088 / 0964-1726 / 20 / 8 / 085009$.

[41] Khan, S., Kintzel, O., Mosler, J. (2012). Experimental and numerical lifetime assessment of Al 2024 sheet, Int. J. Fatigue, 37, pp. 112-122, DOI: 10.1016/j.ijfatigue.2011.09.010.

[42] Breitbarth, E., Besel, M., Reh, S. (2018). Biaxial testing of cruciform specimens representing characteristics of a metallic airplane fuselage section, Int. J. Fatigue, 108, pp. 116-126, DOI: 10.1016/j.ijfatigue.2017.12.005.

[43] Brot, A., Peleg-Wolfin, Y. (2008).The damage tolerance behavior of integrally stiffened metallic structures. 48th Israel Annual Conference on Aerospace Sciences.

[44] Delgado Neto, A.M., Oliveira, T.A.A., Gomes, G. (2019). An efficient GUI update for BEM-FEM mixed mesh generation, Int. J. Comput. Methods Eng. Sci. Mech., 20(3), pp. 256-267, DOI: 10.1080/15502287.2019.1632975.

[45] Gomes, G., Miranda, A.C.O. (2018). Analysis of crack growth problems using the object-oriented program bemcracker2D, Frat. Ed Integrità Strutt., 12(45), pp. 67-85, DOI: 10.3221/IGF-ESIS.45.06.

[46] Gomes, G., Delgado Neto, A.M., Wrobel, L.C. (2016). Modelling and 2D cracks view using dual boundary integral equation. XXXCII Iberian Latin American Congress on Computational Methods in Engineering - CILAMCE, Brasilia-DF.

[47] Gomes, G., Oliveira, T.A.A., Delgado Neto, A.M. (2019). Bemcracker2d: a software package for two-dimensional fatigue crackgrowth analysis. XL Ibero-Latin-American Congress on Computational Methods in Engineering CILAMCE, Natal-RN.

[48] Oliveira, T.A.A., Gomes, G., Evangelista Jr, F., Delgado Neto, A.M. (2018). Multiscale analysis of multiple cracks in aircraft fuselage. XXXIX Ibero-Latin American Congress on Computational Methods in Engineering, University of Technology Compiégne.

[49] Brebbia, C.A. (1978). The boundary element method for engineers., London/New York: Pentech Press/Halstead Press.

[50] Wrobel, L.C., Aliabadi, M.H. (2002). The Boundary Element Method, 2: Applications in Solids and Structures, Wiley.

[51] Pavliots G. A., Stuart A. (2008). Multiscale Methods, vol. 53, New York, NY, Springer New York.

[52] Ranganathan, S.I., Ostoja-Starzewski, M. (2009). Towards scaling laws in random polycrystals, Int. J. Eng. Sci, 47(11-12), pp. 1322-1330, DOI: 10.1016/j.ijengsci.2009.05.003.

[53] Song, W., Krishnaswamy, V., Pucha, R. V. (2016). Computational homogenization in RVE models with material periodic conditions for CNT polymer composites, Compos. Struct., 137, pp. 9-17,

DOI: $10.1016 /$ j.compstruct.2015.11.013. 
[54] Zabihyan, R., Mergheim, J., Javili, A., Steinmann, P. (2018). Aspects of computational homogenization in magneto-mechanics: Boundary conditions, RVE size and microstructure composition, Int. J. Solids Struct., 130131, pp. 105-21, DOI: 10.1016/j.ijsolstr.2017.10.009.

[55] Zhu, F.-Y., Jeong, S., Lim, H.J., Yun, G.J. (2018). Probabilistic multiscale modeling of 3D randomly oriented and aligned wavy CNT nanocomposites and RVE size determination, Compos. Struct., 195, pp. 265-275, DOI: $10.1016 /$ j.compstruct.2018.04.060.

[56] Carniel, T.A., Klahr, B., Fancello, E.A. (2019). On multiscale boundary conditions in the computational homogenization of an RVE of tendon fascicles, J. Mech. Behav. Biomed. Mater., 91, pp. 131-138, DOI: $10.1016 /$ j.jmbbm.2018.12.003.

[57] Johnson, K.L. (1985). Contact Mechanics, Cambridge University Press. 